\title{
Functional Anatomy: Macroscopic Anatomy and Post-mortem Examination
}

\author{
Ángel Guerra
}

\begin{abstract}
Understanding the relationship between form and function of living beings is an intimidating challenge. The recognition and interpretation of physiological and pathological processes require a previous knowledge of regular morphology and anatomy of the external and internal structures and organs of any living creature. Cephalopods span an awesome range of shapes and scales, and the variations between species are crucial for correct interpretations. This chapter covers the gross morphological and anatomical main characteristics of different cephalopod species, as well as necropsy protocols and methods of euthanasia. This knowledge is decisive to a suitable understanding of the modifications caused by injury, infection, or disease, especially for those people who are not familiar with these remarkable marine molluscs.
\end{abstract}

\section{Keywords}

Cephalopods • Gross morphology • Functional anatomy • Euthanasia • Necropsy

\subsection{Classification}

The Cephalopoda is an ancient class of the Phylum Mollusca dating from the Upper Cambrian Period (around 500 million years ago; mya). Cephalopods constitute one of the most complex groups of invertebrates and the most evolved of molluscs. This group has been among the dominant large predators in the ocean at various times in geological history. Its evolution is related directly to the development of low-pressure buoyancy mechanisms. They have acquired the ability to regulate buoyancy, followed by reduction and internalization of the shell and the development of the mantle musculature. Some 17,000 fossil species are known, most of them provided with an outer calcareous shell, whose abundance and distribution have experience important fluctuations throughout the different geologic eras. Clearly, the lineages of extinct taxa were prolific and diverse.

\footnotetext{
Á. Guerra $(\bowtie)$

Ecology and Biodiversity Department, Institute of Marine

Research, Spanish National Research Council (CSIC), 36208

Vigo, Pontevedra, Spain

e-mail: angelguerra@iim.csic.es
}

Palaeontologists have identified three distinct fossil clades that are entirely extinct. All members of these clades were squid-like, but had straight external shells. They flourished in Palaeozoic oceans between the Ordovician (488 mya) and Triassic periods (200 mya). The shells of some of these species reached nearly $10 \mathrm{~m}$ in length. The most well known of these fossil records are the nautiloids, ammonoids, and belemnites. Some of the shelled ammonites that were the dominant elements of the marine fauna during the Mesozoic were of $3 \mathrm{~m}$ in diameter. Increase in brain size and complexity, development of effective sense organs, and changes in the skin concurred to the development of sophisticated behaviours. These traits make cephalopods the most active and intriguing of the molluscs (Nixon and Young 2003).

There are two major divisions within present-day cephalopods: the Nautiloidea with six species of the pearly nautilus (Fig. 3.1), which are the only living cephalopods with outer shells, and the Coleoidea, which is represented by about 800 species, containing the cuttlefishes and bobtail squids (Fig. 3.2), long-fin and short-fin squids (Fig. 3.3), vampire squids, Dumbo octopuses and octopods. This last group includes Argonauta species whose females produce an 
Class: Cephalopoda Cuvier, 1797

Subclass: Nautiloidea Agassiz, 1847

Family: Nautilidae Blainville, 1825 (Pearly or chambered nautilus)

Subclass: Coleoidea Bather, 1888

Superorder: Decapodiformes Leach, 1817

Order: Spirulida Haeckel, 1896

Fam: Spirulidae Owen, 1836

Order: Sepioidea Naef, 1916

Suborder: Sepiida Keferstein, 1866

Fam: Sepiidae Keferstein, 1866

Suborder: Sepiolida Naef, 1916

Fam: Sepiadariidae Fischer, 1882

Fam: Sepiolidae Leach, 1817 (Bobtail squids)

Order: Myopsida Naef, 1916

Fam: Australiteuthidae Lu, 2005

Fam: Loliginidae Lesueur, 1821 (Long-fin squids)

Order: Oegopsida Orbigny, 1845

Fam: Architeuthidae Pfeffer, 1900 (Giant squid)

Fam: Brachioteuthidae Pfeffer, 1908

Fam: Batoteuthidae Young and Roper, 1968

Fam: Chiroteuthidae Gray, 1849

Fam: Joubiniteuthidae Naef, 1922

Fam: Magnapinnidae Vecchione and Young, 1998

Fam: Mastigoteuthidae Verrill, 1881

Fam: Promachoteuthidae Naef, 1912

Fam: Cranchiidae Prosch, 1847

Fam: Cycloteuthidae Naef, 1923

Fam: Ancistrocheiridae Pfeffer, 1912

Fam: Enoploteuthidae Pfeffer, 1900

Fam: Lycoteuthidae Pfeffer, 1908

Fam: Pyroteuthidae Pfeffer, 1912

Fam: Gonatidae Hoyle 1886

Fam: Histioteuthidae Verrill, 1881

Fam: Psychroteuthidae Thiele, 1920

Fam: Lepidoteuthidae Naef, 1912

Fam: Octopoteuthidae Berry, 1912

Fam: Pholidoteuthidae Voss, 1956

Fam: Neoteuthidae Naef, 1921

Fam: Ommastrephidae Steenstrup, 1857 (Short-fin squids)

Fam: Onychoteuthidae Gray, 1847

Fam: Thysanoteuthidae Keferstein, 1866

Superorder: Octopodiformes Berthold and Engeser, 1987

Order: Vampyromorpha Robson, 1929

Fam: Vampyroteuthidae Thiele, in Chun, 1915 (Vampire squids)

Order: Octopoda Leach, 1818

Suborder: Cirrata Grimpe, 1916 (Dumbo octopuses or Cirroctopods)

Fam: Cirroteuthidae Keferstein, 1866

Fam: Stauroteuthidae Grimpe, 1916

Fam: Opisthoteuthidae Verrill, 1896

Suborder: Incirrata Grimpe, 1916

Fam: Alloposidae Verrill, 1881

Fam: Argonautidae Cantraine, 1841

Fam: Ocythoidae Gray, 1849

Fam: Tremoctopodidae Tryon, 1879

Fam: Eledonidae Grimpe, 1921

Fam: Octopodidae Orbigny, 1839 (Octopuses)

Fam: Enteroctopodidae Strugnell et al., 2013

Fam: Amphitretidae Hoyle, 1886

Fam: Bathypolypodidae Robson, 1932 
Fam: Megaleledonidae Taki, 1961

Order uncertain

Superfamily: Bathyteuthoidea nov.

Fam: Bathyteuthidae Pfeffer, 1900

Fam: Chtenopterygidae Grimpe, 1922

Fam: Idiosepiidae Fischer, 1882

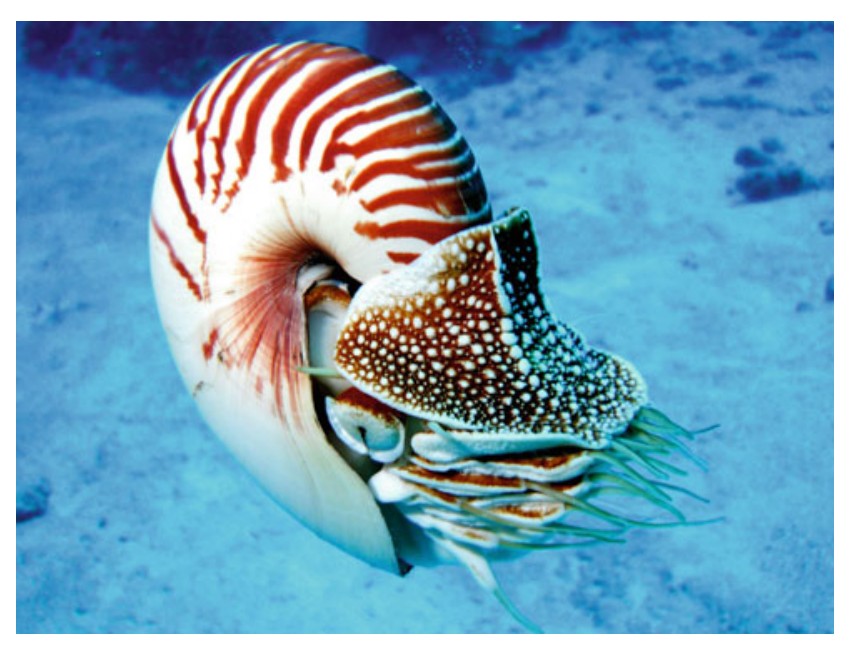

Fig. 3.1 Nautiluses or chambered nautiluses are the sole living cephalopods with an external shell

external calcareous structure (Fig. 3.4), which is not a true shell but a brood chamber.

Currently, the most widely accepted classification is the proposed by Young et al. (2018):

\subsection{Ecology: General Aspects}

As indicated by Boyle and Rodhouse (2005): «Any ecological approach always tries to take account of the interacting factors of evolution, genetics, physiology, and behaviour of the organisms as well as their relationships with the stochastics parameters of the environment. Consequently, these studies involve multidisciplinary approaches, which are not always easy to obtain for marine animals». This difficulty also affects cephalopods which occupy a great variety of habitats in all of the world's oceans (Fig. 3.5) and have a large variety of life history strategies. Another difficulty with these studies is the disparity of knowledge currently held about cephalopod species, which, on the other hand, increases day by day. For these reasons, we are going to provide here some generalities concerning the great ecological categories in which it is possible to classify living cephalopods.

The broad category of "coastal and shelf species" (neritic species) covers the relatively well-known cephalopod groups. The aphorism "live fast, die young" describes quite well the life history strategy of these coleoid cephalopods, which have epipelagic and benthic habitats. Nevertheless, as indicated by O'Dor (In Darmaillacq et al. 2014), «that phrase "live fast, die young" perhaps should be expanded to "live fast and smart, to leave offspring fewer enemies». Specifically, the available evidence of species of neritic cephalopods is that they complete their life cycle in one or two years and in some small species even in a shorter time. Beside this short lifespan, other characteristics shared by all members of this category are a similar type of predation, which places them at the upper trophic levels of the ecosystem. Like most cephalopods, neritic species have a single ovarian cycle. However, many of them have long spawning periods, in which the larger peak of new hatchlings is synchronized with environmental conditions providing them with suitable oceanographic factors and appropriate prey, which ensures high survival rates, but, conversely, noteworthy mass mortality. Consequently, cephalopod populations are highly unsteadied responsive to change in physical, chemical, and biological environment. Fecundity of the species within this category is very variable, from a few hundred eggs in cuttlefish, to several hundreds of thousands in octopus. Cephalopods do not have a true larva, because they lack of a distinct metamorphosis. Hatchlings of a number of species are planktonic and have a distinctively mode of life from older conspecifics (paralarvae). The neritic species share some degree of dependency on the seabed: some of them lay and eat at the bottom (demersal species, e.g. Loliginidae), but others, such as cuttlefish and octopuses, are truly benthic species.

The "oceanic and deep-sea category" of species encompasses the taxonomically diverse families of epi-, meso-, and bathypelagic, as well as bathybenthic cephalopods. The ecological knowledge about this group is still scarce. Although they share many basic characteristics, their lifestyles are more different between these taxa than with the neritic forms.

Like all division into categories, the one we present here is artificial and there are some species of difficult location, even within the same family. Thus, for example, in the Ommastrephidae, there are several species of different genera (Ommastrephes, Sthenoteuthis, Martialia, Dosidicus) that are truly ocean dwellers. Conversely, species of the genus Illex, Todadores, Todaropsis, and Nototodarus, although they typically have an offshore distribution, are frequently present on the continental shelves. There are many other examples of this or similar scenarios, and Jereb and Roper $(2005,2010)$ and Jereb et al. (2016) catalogues provide account for all families.

In any case, cephalopods are important to the ecosystem as both predator and prey as well as reservoirs of parasites. 


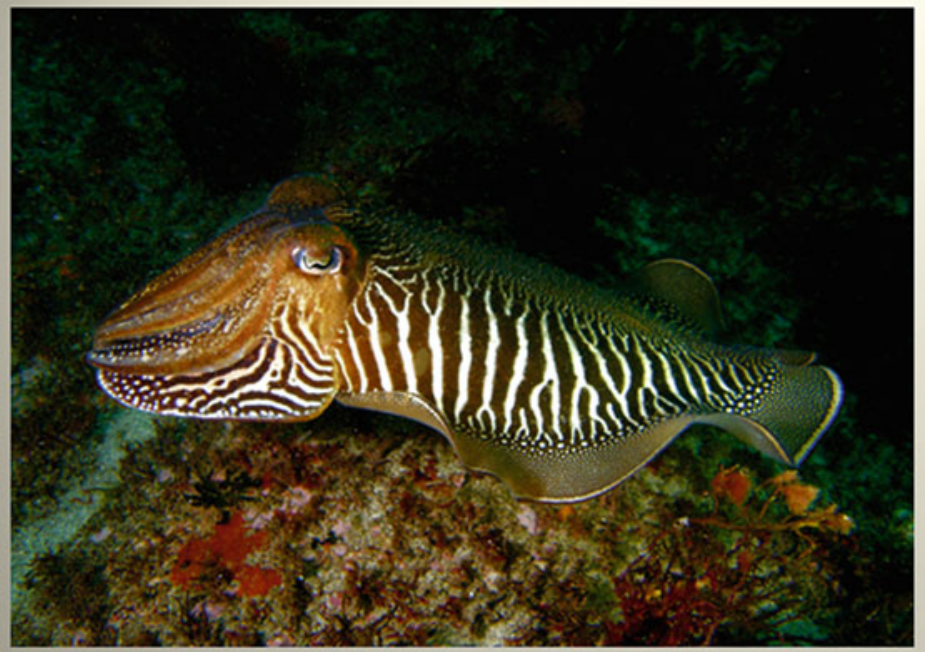

\section{Common cuttlefish Sepia officinalis}

Atlantic bobtail squid Sepiola atlantica

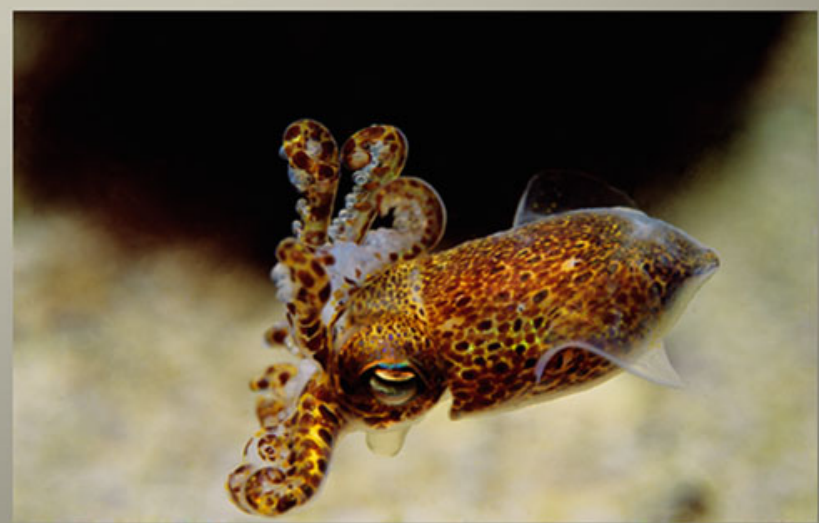

Fig. 3.2 Two species representatives of the order Sepioidea. Photographs by J. Hernández-Urcera and J. L. González

\subsection{Fisheries and Aquaculture}

Cephalopod catches worldwide account for around 4 million tons per year in 2016 (about $4 \%$ of total marine products). Although in recent times the total world catch from marine and freshwater fish stocks appears to have peaked and may be declining, the catch of cephalopods has continued to increase as fishers concentrate efforts away from more traditional finfish resources. Cephalopods fisheries can be divided between small-scale fisheries (SSFs) and industrial fisheries (IF). The SSFs are of great importance in terms of job opportunities, and they contribute significantly to the economy of many coastal communities. Methods of capture in SSFs are very diverse (pots, traps, lures, etc.), and the catches are mainly consumed in fresh. IF methods of capture are mainly jigging and trawling, and the catches are mainly commercialized frozen. Numerous species are caught in
SSFs; however, IF are supported by a few species, mainly belonging to the families Loliginidae, Ommastrephidae, and Octopodidae (see Arkhipkin et al. 2015 for review).

Historically, the consumption of cephalopod products has been highest in the countries of Asia (Japan, Thailand, Taiwan, and China). Among European countries, Spain, Portugal, Italy, and Greece are the traditionally high consumers of cephalopods. In the rest of the globe, per capita cephalopod consumption is low.

The life cycle characteristics of cephalopods mean that their fisheries are intrinsically difficult to assess and manage. The level of exploitation of some stocks exploited in IF is quite high, and some of them are actually overexploited. Increasing of scientific knowledge for assessment and management purposes is needed.

The increasing demand of cephalopods and some of biological traits (high growth rates and short life spans) make cephalopods ideal candidates for commercial 


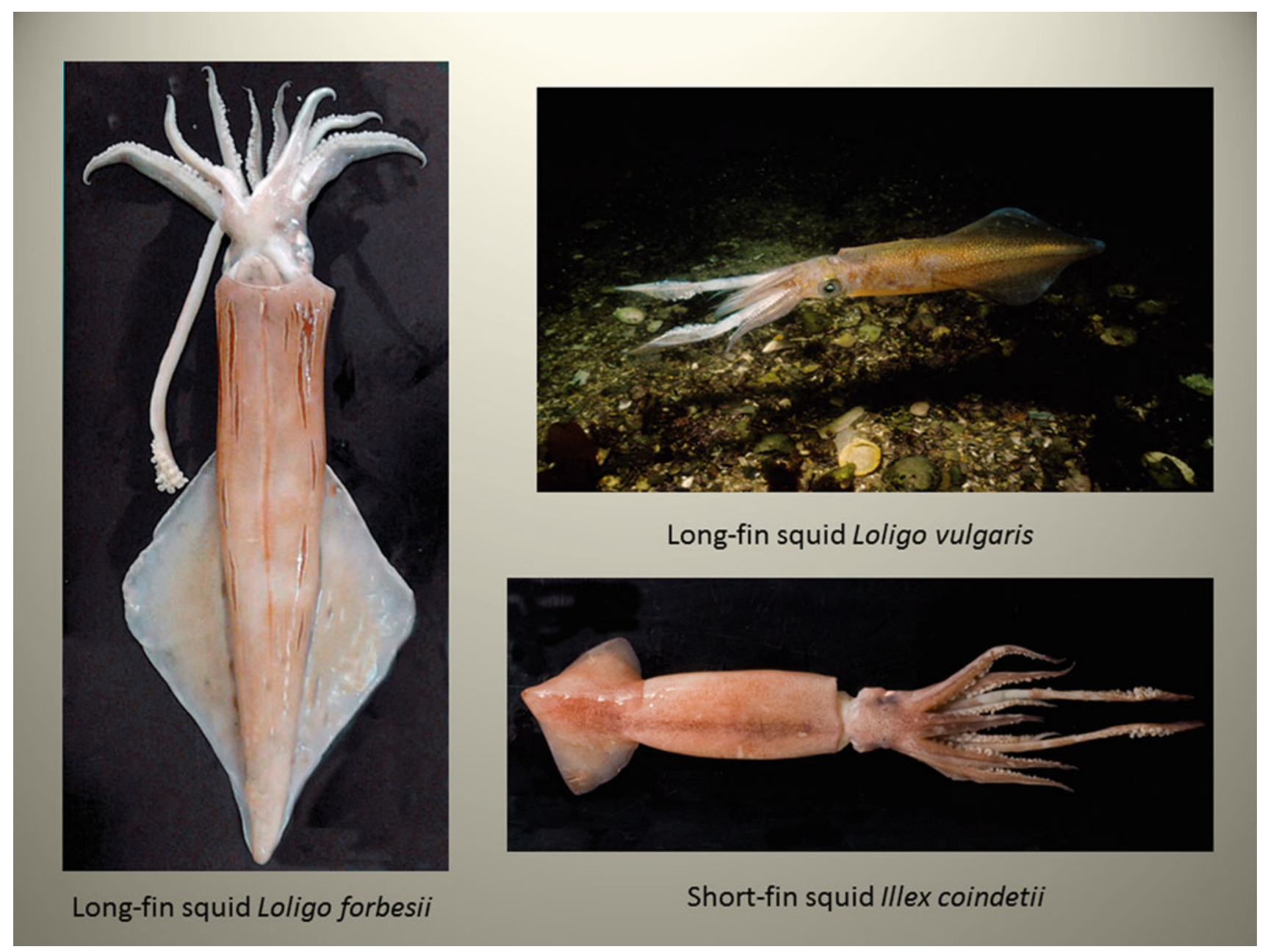

Fig. 3.3 Two species representatives of the order Myopsida (genus Loligo, family Loliginidae) and one of the order Oegopsida (genus Illex, family Ommastrephidae). Courtesy of A. Escánez and J.L. González

aquaculture since they have the potential to rapidly reach market size. As pointed out by Louise Allcock, former President of the Cephalopod International Council (CIAC), in the preface of the book "Cephalopod Culture" by Iglesias et al. (2014), «this is a pioneering text, which draws together a vast array of knowledge on cephalopod culture and provides the foundations for further advances in this significant field». Moreover, some species are used as model organisms in neurobiology, robotics, restocking, pharmaceutical exploitation of antibacterial anticancer activities reported from the ink sac, the use of modified cuttlebone in tissue engineering, the many and varied used of cuttlefish oil, and to study the cephalopod immune system. In consequence, small-scale culture of some species has become scientifically important in the latter half of the twentieth century. Nevertheless, the industrial culture of cephalopods is still in an incipient state. There are, however, some advances; one of them is successfully culture octopuses with large hatchlings using a completely artificial diet. As a result of the numerous studies carried out since 1990 to present days, many culture protocols had been optimized. At present, only 19 species of cephalopods are being cultivated worldwide: three Nautilus and Allonautilus species, four cuttlefish, two sepiolids, three loliginid squids, and seven octopods. The main bottlenecks in cephalopod culture were identified to be nutrition and physiology. 


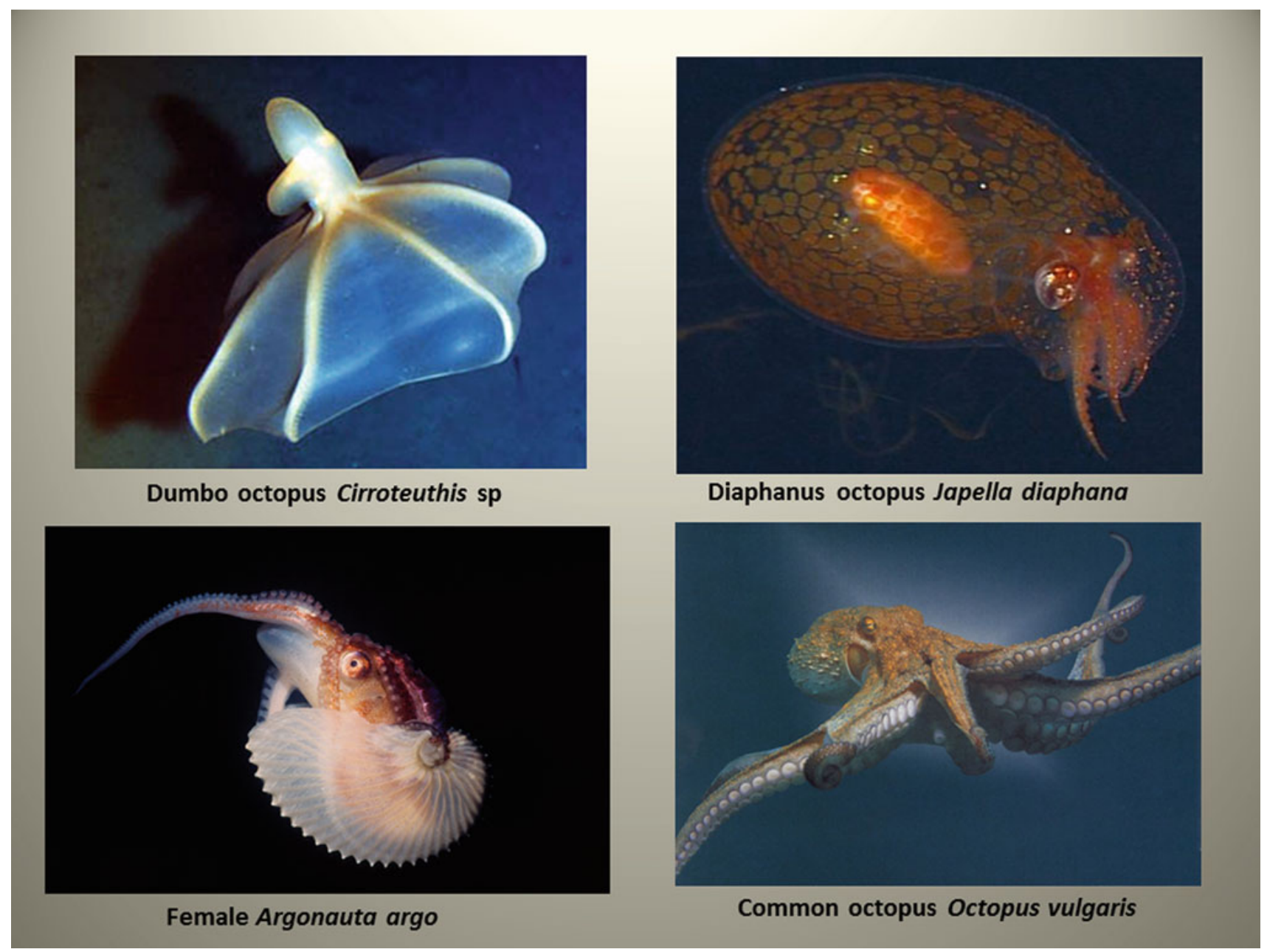

Fig. 3.4 Dumbo octopus (Cirroteuthis sp) is representative of the order Octopoda, suborder Cirrata; Japetella diaphana is a pelagic Octopoda; Argonatuta argo and Octopus vulgaris are representatives of the order Octopoda, suborder Incirrata. Courtesy of J.L. González

\subsection{Morphology and Anatomy of the Adult}

Modern cephalopods (subclass Coleoidea) have bilateral symmetry, and the body is divided into two defined parts: the cephalopodium or anterior part and the visceropalium or posterior part. The cephalopodium includes the head, the appendages that surround the mouth and the funnel; the visceropalium comprises the mantle, the cavity of the mantle and its organs, as well as the shell and the fins, the latter if present (Mangold 1989).

\subsubsection{External Morphology}

\subsubsection{Size}

The basic measure of cephalopods is the dorsal length of the mantle (ML), but also ventral mantle length (VML) can be used. In Sepioidea, Myopsida, and Oegopsida, ML is the distance between the antero-dorsal margin of the mantle and the posterior apex of the mantle (Fig. 3.6). In the Octopodiformes, ML is measured from the back of the body to an imaginary line that would connect the centre of both eyes (Fig. 3.7). Sometimes, other measures such as the total length (TL), which is the distance between the longest arm, or the extended tentacle, and the back of the animal's mantle, are used. Mantle length of adult cephalopods varies between $6 \mathrm{~mm}$ in the genus Idiosepius to around $2 \mathrm{~m}$ in the giant squid Architeuthis dux.

\subsubsection{External Form}

The head is usually separated from the mantle by the nuchal constriction. It carries the oral appendices and the eyes, which are usually spherical and of similar size, although in Histioteuthis the left eye is much larger than the right. In the occipital region, the head may be completely fused with the mantle or attached to it by a nuchal cartilage. A cartilaginous capsule contributes to the shape and volume of the head. 


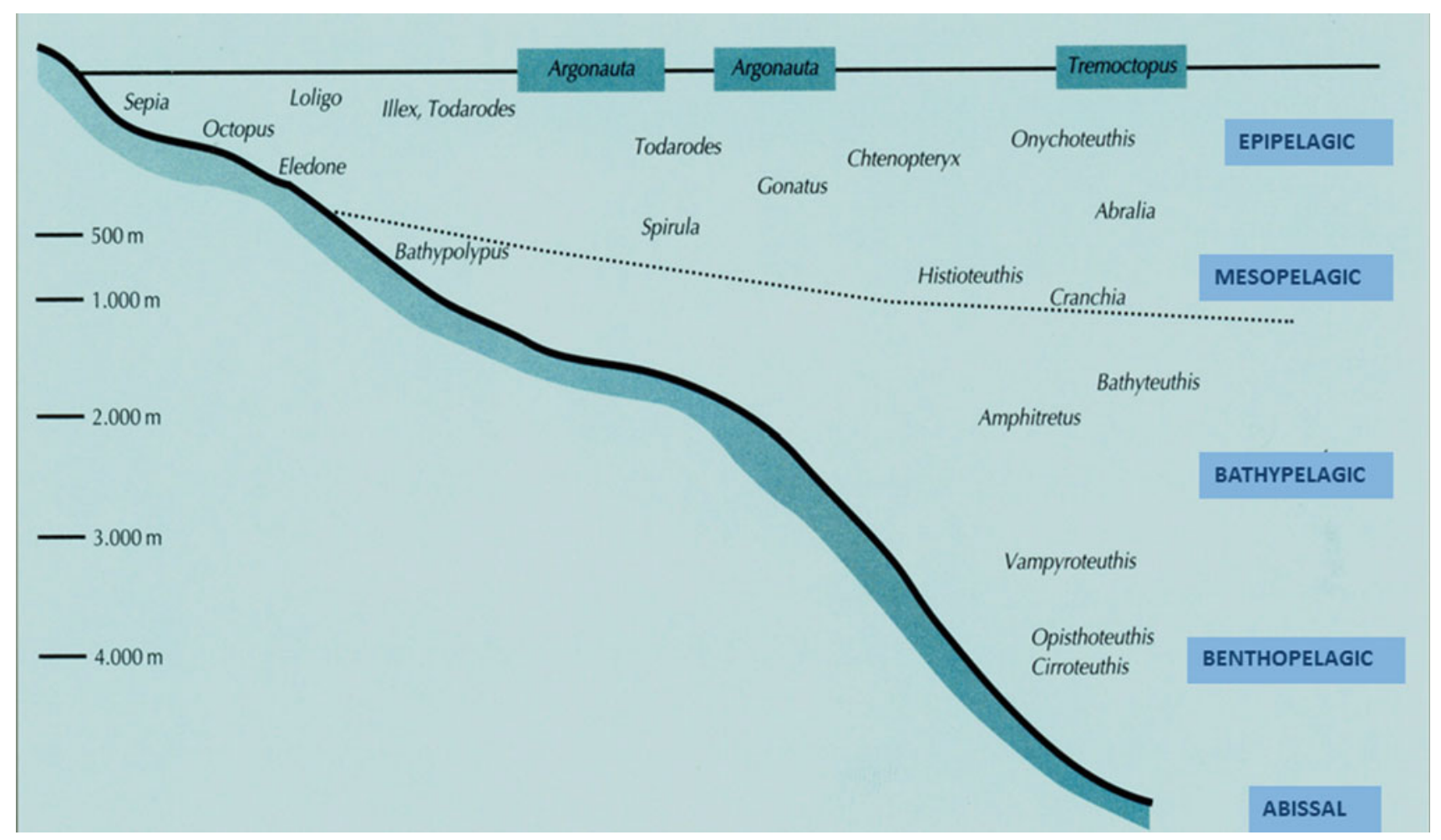

Fig. 3.5 Distribution with habitat and depth of selected genera characteristics of different marine zones

This capsule is like a skull that surrounds and protects the brain. On both sides of the head, near the neck, the olfactory organs are located.

Decapodiformes cephalopods have ten muscular appendages of two types, differing according to their length: eight arms (shorter) and two tentacles (longer). In contrast, Octopodiformes have only eight arms, lacking tentacles, although the arms are usually longer in proportion to body size than Decapodiformes. Each pair of arms is generally different in size from the other pairs. In Vampyroteuthis, two of its ten arms have been transformed into long and thin filaments that are retracted in a pair of bags placed between the dorsal and dorso-lateral arms. The species of Nautilus have 63-94 arms or short tentacles. The arms are often numbered from the dorsal pair to the ventral (which is well defined because it is the side of the animal where the funnel opens). This gives rise to the "brachial formula" (Figs. 3.6 and 3.7). A brachial formula such as 4.13.2 indicates that the fourth pair of arms (or ventral) to the right of the animal's body is longer than the second (or dorso-lateral), and this one longer than the first (or dorsal), which is longer than the third. The numbers of the brachial formula can be Arabic or Roman (Figs. 3.6 and 3.7). This formula has taxonomic value, especially the Octopodiformes (Jereb and Roper 2005, 2010 and Jereb et al. 2016 catalogues provide illustrated glossaries of technical terms and measurements).
The arms of Sepioidea, Myopsida, and Oegopsida are attached to the outer lip by a buccal membrane that has six, seven, or eight folds. These folds are attached to the dorsal and ventral margins of the arms through the buccal connectives. The arrangement of such bonds has taxonomic value and is also expressed by a formula. Thus, a DDVV formula indicates that the buccal connectives are attached to the dorsal margin of the first two pairs of arms and to the ventral of the following two pairs. Vampyroteuthis and all Octopodiformes lack buccal connectives.

The cross section of the arms of Sepioidea, Myopsida, and Oegopsida is generally triangular. The inner surface (oral) is flattened, while the outer (aboral) surface is angular. The suckers are arranged on the oral surface, usually in two rows, although there may be more. Suckers are provided with denticulate or smooth chitinous rings. Arm suckers have been converted into hooks in some oceanic species of Oegopsida (e.g. Taningia danae). Along the lateral angle of the oral surface of the arms, there are web-like integument protective membranes, generally supported by muscular rods called trabeculae. These protective membranes are well developed in some species. Thus, for example, in Histioteuthis species join two pairs or more arms, while in some Ommastrephidae (e.g. Ommastrephes bartramii), the ventral protective membranes of arm III are very wide and in adult females expand into a large, triangular, membranous lobe. 


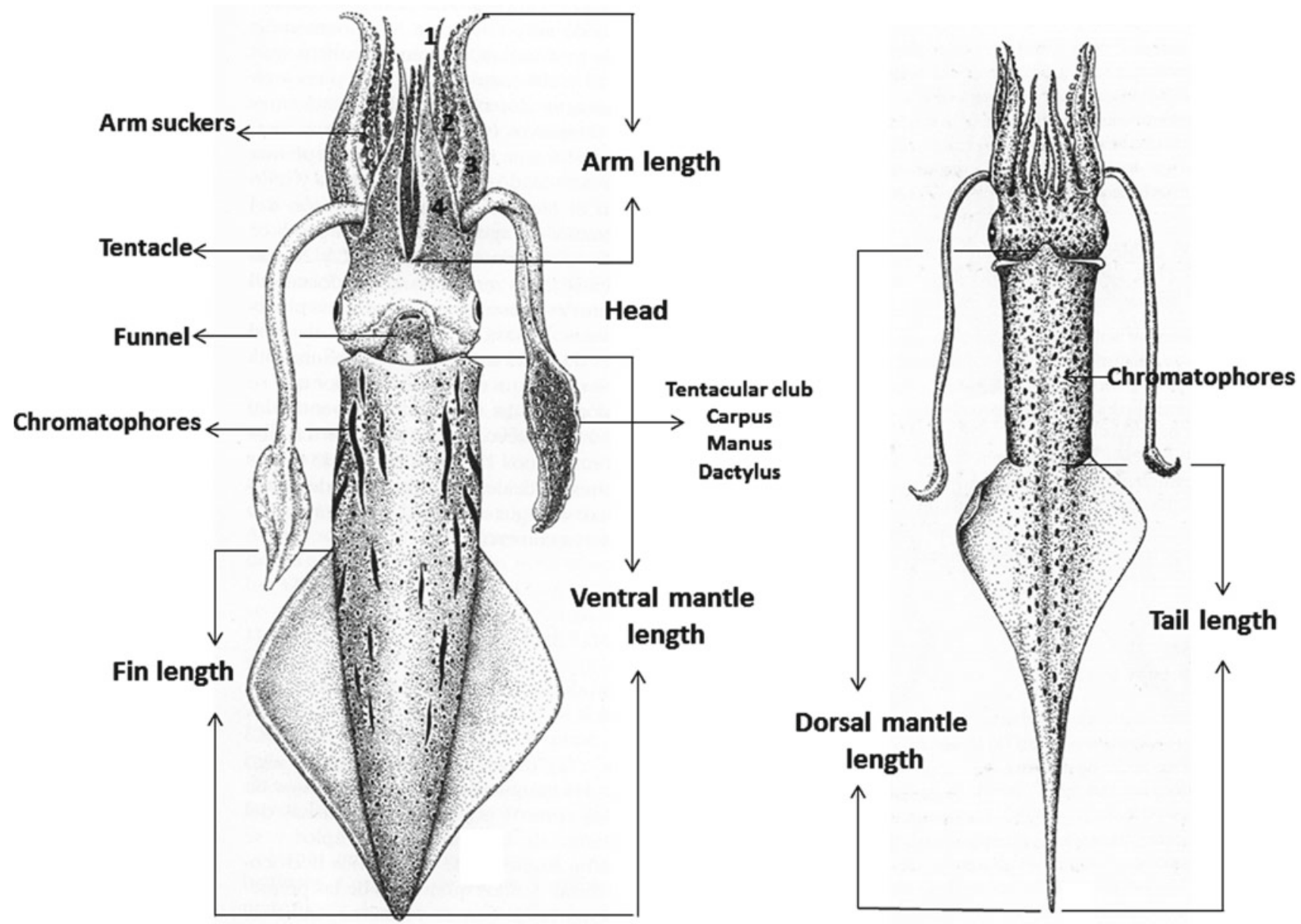

Fig. 3.6 Nomenclature of diverse parts of the body of Loliginidae and points between which the body measurements should be taken (Drawings from Guerra 1992)

The so-called swimming keels are flattened and muscular expansions located on the aboral side of some arms to render them more hydrodynamic.

Vampyroteuthis and Octopodiformes cross section of the arms is, generally, circular. All arm suckers of Octopodiformes lack of chitinous rings. In certain cases, as in the males of some species of Octopoda Incirrata, there are several modified suckers, generally larger than the others, which play a role in courtship. Both Vampyromorpha and Octopoda Cirrata have elongate, fleshy, finger-like papillae (cirri) along the lateral edges of the oral surface of the arms, which length is variable. Cirri are mechanoreceptors. A membranous sheet of greater or lesser extent can be present between the arms of many Octopodiformes (Fig. 3.7a); this web gives an umbrella-like appearance when the arms are spread out.

One (or more) arm in male cephalopods is modified to be used transferring spermatophores to the female. This arm (s) is called hectocotilized arm and the modified portion hectocotylus. Modifications may involve suckers, sucker stalks, protective membranes, trabeculae, and a section of the arm. The last occurs in the distal tip of the Cirrata and Incirrata Octopodiformes. In these cases, along the hectocotilized arm, there is a spermatophore groove, which end open into a structure formed by the ligula and the calamus (Fig. 3.7b). The ligula is a spatulate or spoon-shaped, terminal structure of the hectocotylus, which usually contains a series of transverse ridges and grooves on the oral surface. The calamus is a conical papilla or projection of the base of the ligula at the distal terminus of the sperm groove, distal to the last sucker.

The tentacles are two long appendages in Decapodiformes, used for prey capture and capable of considerable extension and contraction. The tentacles can be retracted into open depression or pockets located in the antero-ventral surface of the head between the bases of the ventro-lateral (3) and ventral pair of arms (4) in all Sepioidea species, but not in Myopsid and Oegopsid squids. A tentacle is composed by a peduncle, the carpus or fixing apparatus, and the tentacular club, which is an expansion of the distal part 


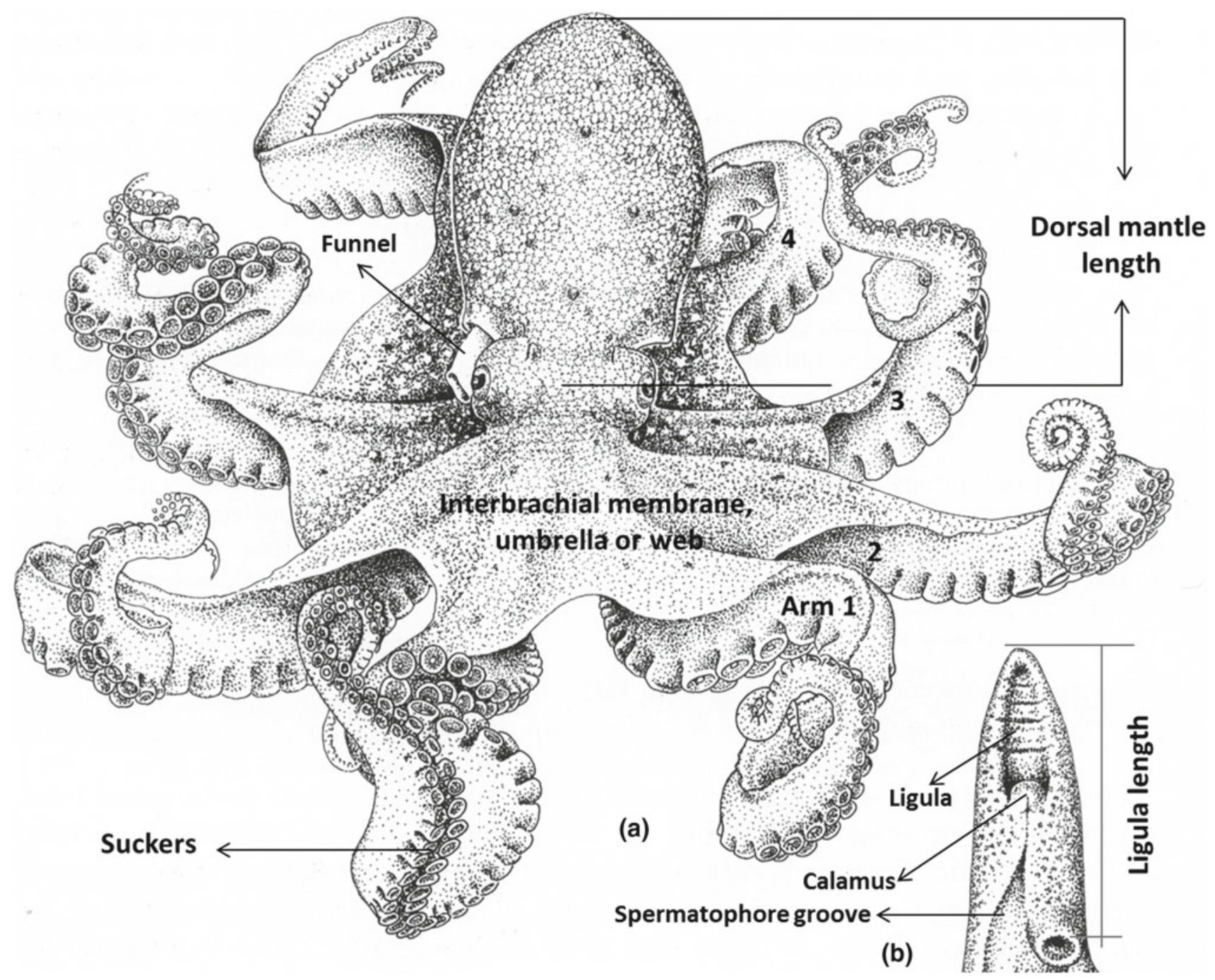

Fig. 3.7 Main measurements and terms in Octopoda Incirrata. a Body; b hectocotilized arm. (Drawings from Guerra 1992)

(Fig. 1.6). The central or "hand" portion of the club may have suckers and/or hooks. The distal, terminal section of the club, often characterized by suckers of reduced size is the dactylus.

The ventral, subconical tube through which the water is expelled from the mantle cavity during locomotion and respiration, and that also serve to expelled ink, reproductive and waste products, is the funnel. In Sepioidea, Myopsida, and Oegopsida, the funnel is located within a depression in the posterior-ventral surface of the head called funnel groove. However, in Octopodiformes, it is embedded in the tissues of the head, leaving only the apical region free. The funnel groove of Oegopsid squids has a series of structures with taxonomic value. Thus, in some genera (e.g. Todorodes, Illex), there are transverse, membranous folds of skin that form a pocket in the anterior end of the funnel groove, called foveola. Other genera, like Ommastrephes, have also small shallow pockets lateral to foveola in the funnel groove.
The muscles that support the lateral attachment of the funnel to the head, called funnel-adductor muscle, are generally well developed. In many groups of cephalopods, within the funnel, there is a semilunar muscular flap in the dorsal surface near the distal opening of the funnel-the funnel valve - and also a glandular structure - the funnel organ -, which adopts different forms; the configuration of the funnel organ has taxonomic importance, especially in Cranchiidae and Octopodidae.

The lower lateral margins of the funnel may be fused to the mantle (e.g. Cranchiidae) or be connected to it by a cartilage: the funnel-locking cartilage. The cartilage portion found in the funnel of Sepioidea, Myopsida, and Oegopsida presents a varied morphology, and it is also a character of taxonomic importance. There is also a funnel-locking cartilage in the Argonautoidea superfamily, but the rest of the Octopodiformes lack this structure. The cartilaginous ridge, knob, or swelling on each side of the ventro-lateral, internal 
surface of mantle that locks into the funnel component is called mantle-locking cartilage. Both structures funnel and mantle-locking cartilages form the locking apparatus which is essential for locomotion.

The mantle of cephalopods is basically a muscular sac. The dorsal part of the mantle cavity is small, while the ventral part is larger and lodges the viscera. Cephalopod muscles are arranged in three dimensions in closely packed blocks, which allow rapid and abrupt contractions. The contraction and relaxation of the different types of muscle fibres of the mantle allow the expulsion and entry of water into the mantle cavity. The best-known peripheral nervous system is that of the giant axons, which in three steps from the magnocellular lobe and the paleovisceral lobe of the brain innervate the mantle musculature. These axons have a diameter between 0.5 and $1 \mathrm{~mm}$ (thousand times greater than the axons of mammals). Its reaction potential is so high that the nerve transmission runs at high speed, allowing the extremely rapid, complete, and instantaneous reaction of the pallial musculature to give rise to the incomparable hydrodynamic invention of the jet propulsion.

The mantle musculature in some Oegopsida (e.g. Cranchiidae) and pelagic octopuses (e.g. Japetella diaphana, Fig. 3.4) has been reduced and has a high water content. Many of these species have gelatinous consistency, medusoid aspect, and the walls of the mantle are translucent so that they allow the internal organs to be seen.

The members of the family Lepidoteuthidae have a distinct dermal cushions present on the mantle. These dermal cushions, which are thickening of the skin with abundant vacuoles and connective tissue, are relatively large, diamond, or hexagonal-shaped structures that cover the whole circumference of the mantle and in overlapping arrangement.

Most cephalopods have a pair of fins of varying shapes and sizes. They are located in the back of the mantle in the Myopsida and Oegopsida (Figs. 3.3 and 3.6), in its middle zone in the Octopoda Cirrata (Fig. 3.4) or in its lateral borders in Sepioidea (Fig. 3.2). Octopoda Incirata has no fins. This pair of muscular flaps is used for locomotion, steering and stabilization.

The mantle of many Myopsida and Oegopsida has a posterior narrow extension or tail, in which length may be very long (Fig. 3.3). The end of the fins and the beginning of the tail often overlap. This posterior extension of the body is often very long in paralarval stages. Some species (e.g. Alloteuthis subulata or A. africana) show a lengthening of the tail as the males mature sexually and constitute a secondary sexual character.

\subsubsection{Integumental System: The Skin and Elements Contributing to Colour and Body Patterns}

The epidermis contains three main kinds of cells: epithelial columnar cells, gland cells, and sensory cells. Immediately bellow the epidermis, there is a layer (dermis) that possesses a series of sacs with pigment- the chromatophores, which are typically only red, yellow, or brown and determine colour changes in camouflage (Fig. 3.8). Other colours are attainable by using a second layer of structures in the cephalopod skin called iridophores and leucophores, which are located in the dermis. Iridophores are stacks of very thin cells that are capable of reflecting light back at different wavelengths and possibly different polarities. Cuttlefish and octopuses possess an additional type of reflector cells called leucophores. They are cells that scatter full spectrum light so that they appear white. By combining reflection from the iridophores and leucophores with the correct patterning of chromatophores, the cephalopod can create a very convincing copy of the surrounding conditions. The rest of the dermis consists of an outer tunic with collagen fibres, the musculature, a layer with nerve fibres and blood vessels, and, finally, an inner tunic. In Sepioidea and Incirrata Octopodiformes, there is a complex musculature that changes their skin from smooth and flat to rugose and three-dimensional. The organs responsible for this physical change are the skin papillae. Skin texture is an important contribution to body pattering. The photophores, which are bioluminescence cells, are also located in the skin and in different regions of the body, for instance, around the eyes, in the ventral part of the mantle, arms, tentacles, and even inside the mantle cavity over the ink sac.

\subsubsection{Functional Anatomy}

\subsubsection{The Shell}

At present, the only representatives of this class of the phylum Mollusca with external shell are Nautilus and Allonautilus. The shell of these cephalopods is divided into chambers bounded by transverse septa, the latter occupying the animal. Through the septa, there is a tissue cord tube-like form or siphuncle, which intervenes in the control of the buoyancy of the animal, regulating the relative volume of gases and liquids present in the chambers of the shell.

The rest of the cephalopods present an internal shell, as it occurs in cuttlefish, squids, or it is totally vestigial, or it does not exist as such (Incirrata). Spirula has a flattened spiral 


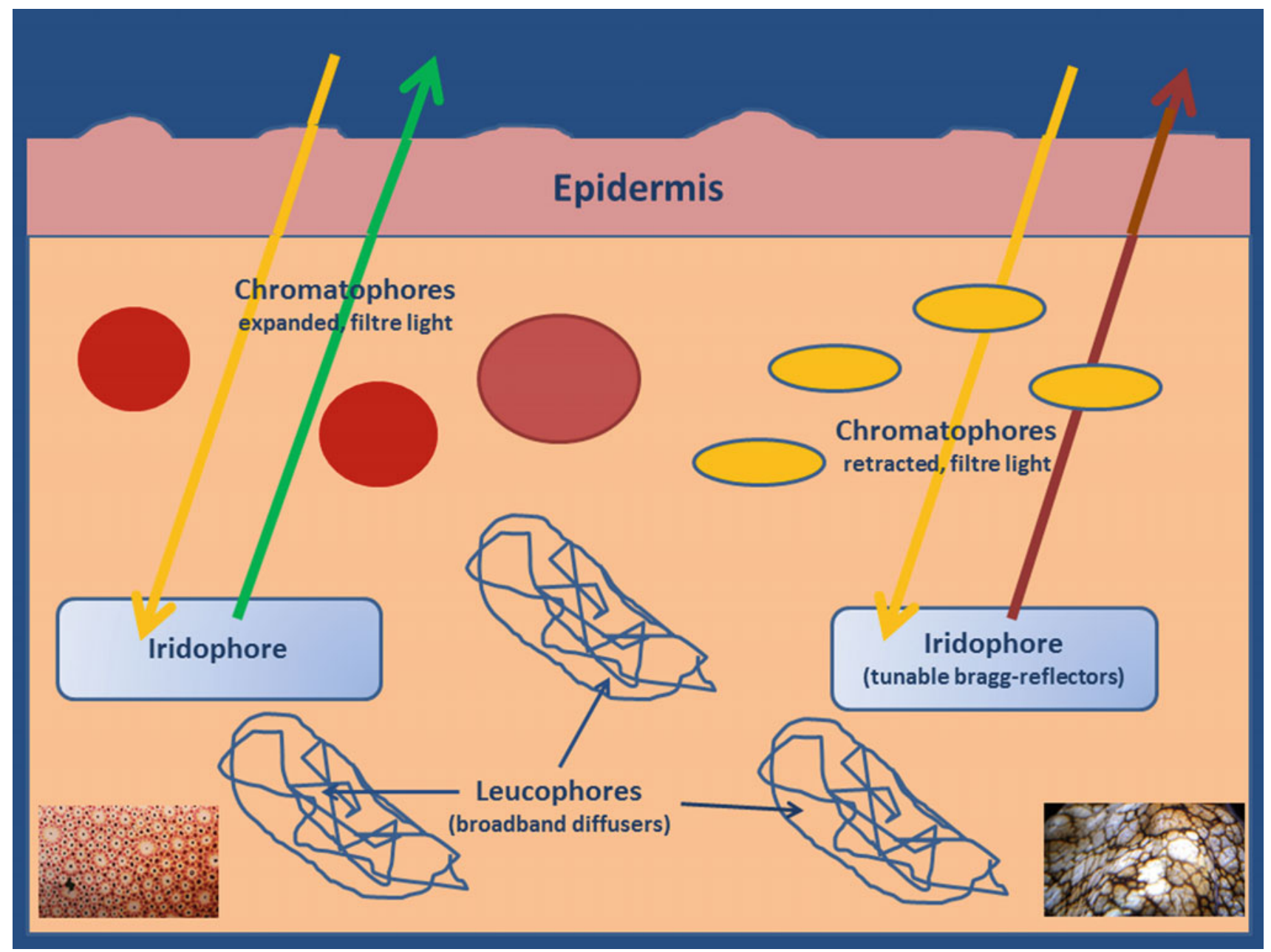

Fig. 3.8 Diagram showing the elements that contribute to colour body patterns and their arrangement in the skin

internal shell that does not intervene in the protection of the animal, although it contributes to maintaining the body shape and acts as a hydrostatic skeleton. The cuttlebone of the cuttlefishes (Sepia spp) is an intricate structure composed of a dorsal shield and ventrally placed chamber complex. It is composed of calcium carbonate in its aragonite polymorph mixed with a small amount of organic matter, a complex of $\beta$-chitin and protein. In ventral plan view, the chamber complex consists of the posterior siphuncular zone, which is characterized by a series of striae corresponding each to the posterior end of one chamber, and the septum of the last-formed chamber. In dorso-ventral vertical section, each chamber is composed of a complex arrangement of horizontal septa and membranes and vertical pillars and membranes, intervening in the control of the buoyancy of the animal by regulating the amount of gas and liquid present in such chambers.

In the Myopsida and Oegopsida squids, the shell, also called gladius or pen, is reduced to a chitinous sheet with a central axis and two lateral expansions; the pen contributes to maintain the rigidity of the body in longitudinal sense during the convulsive contraction phase of jet swimming, but it has lost its protective function. A number of pelagic from achieve neutral buoyancy by a reduction of the protein content of their tissues and the accumulation of a low-density solution of ammonium chloride either the coelomic space (e.g. Cranchiidae) or in the vacuoles within the musculature and connective tissue (e.g. Architeuthis dux).

Cirrate octopuses possess a well-developed internal shell that supports their muscular swimming fins. This is in contrast to the more familiar, finless, incirrate octopuses, in which the shell remnant is either present as a pair of stylets or absent altogether.

\subsubsection{Respiratory and Circulatory Systems}

Respiratory exchange with the environment occurs through well-vascularized gills suspended in the mantle cavity. Nautilus and Allonautilus species have two pairs of gills, but in all Coleoidea there is only a single pair (Fig. 3.9). Due to the particular orientation of the gills within the mantle 


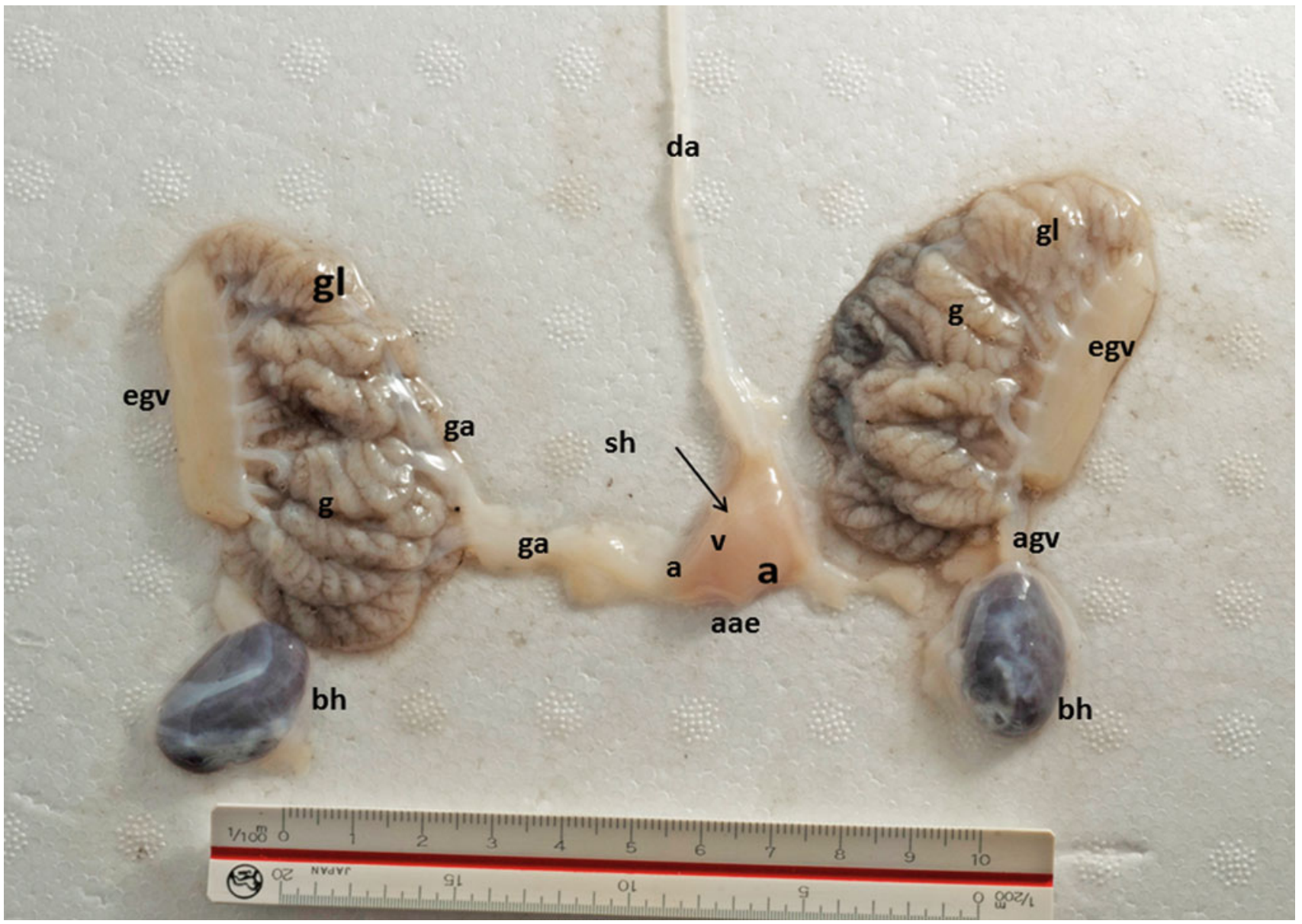

Fig. 3.9 Respiratory and circulatory system of Octopus vulgaris (partial); a: auricle; aae: abdominal aorta exit; agv: afferent gill vessel; bh: branchial or gill heart; da: dorsal aorta; agv; efferent gill vessel; g: gill or branchia; gl: gill lamellae; sh: systemic heart; v: ventricle

cavity, water flows between the lamellae of each gill in the opposite direction of the flow of blood through the tissue. This originates a countercurrent system that maximizes the exchange of gas.

Unlike all other molluscs, cephalopods have a closed circulatory system. This means that blood flows through a series of vessels to return to the heart, rather than bathing organs in the blood fluid as in open circulatory systems.

The core of the cephalopod circulatory system is a series of three beating hearts. This trio of hearts connects to a high pressure system of veins, arteries, and capillaries - unique among all molluscs. Two of the hearts are branchial hearts (Fig. 3.9), which pump blood through the gills for respiration and gas exchange. The third heart is a systemic heart (Fig. 3.9), receiving the blood that drains from the gills and pumping that oxygenated blood to the body system. Each of the three hearts is innervated by a variety of nerves, though it appears that the cardiac ganglion-a cluster of nerves - acts as the controlling pacemaker of the hearts. The two branchial hearts beat simultaneously, followed by the contraction of the systemic heart to supply the body with blood. Blood drains to the branchial hearts by the major veins, known as the anterior and lateral vena cava or vena cava cephalica.

The vessels within the gills are known as afferent branchial vessels, which drain back to the main ventricle of the systemic heart. Blood is then pumped from the systemic heart to the body via the main cephalic artery.

Oxygenate cephalopod blood is a blue colour due to the presence of copper-containing respiratory pigment haemocyanin in solution in the blood, because cephalopods lack of erythrocytes. The oxygen carrying capacity of the haemocyanin is less efficient that the vertebrate haemoglobin. Cephalopods exhibit the highest rates of aerobic metabolism among the marine invertebrates. However, it is very variable, depending of some environmental factors such as water temperature, but also on the performance of their haemocyanins (Pörtner et al. 1994). Accordingly with oxygen affinity, cephalopods can be divided into three groups: octopuses and some sluggish squids, with relatively low oxygen capacity; fast-swimming squids; and Sepia species. 
Fig. 3.10 Sepia officinalis digestive system; an: anus; asg: anterior salivary glands; be: beak or mandibles; bm: buccal mass; cae: caecum; dg: digestive gland (bilobulate); dgda: digestive gland duct appendages; int: intestine; insd: Ink sac duct; oe: oesophagus; st: stomach

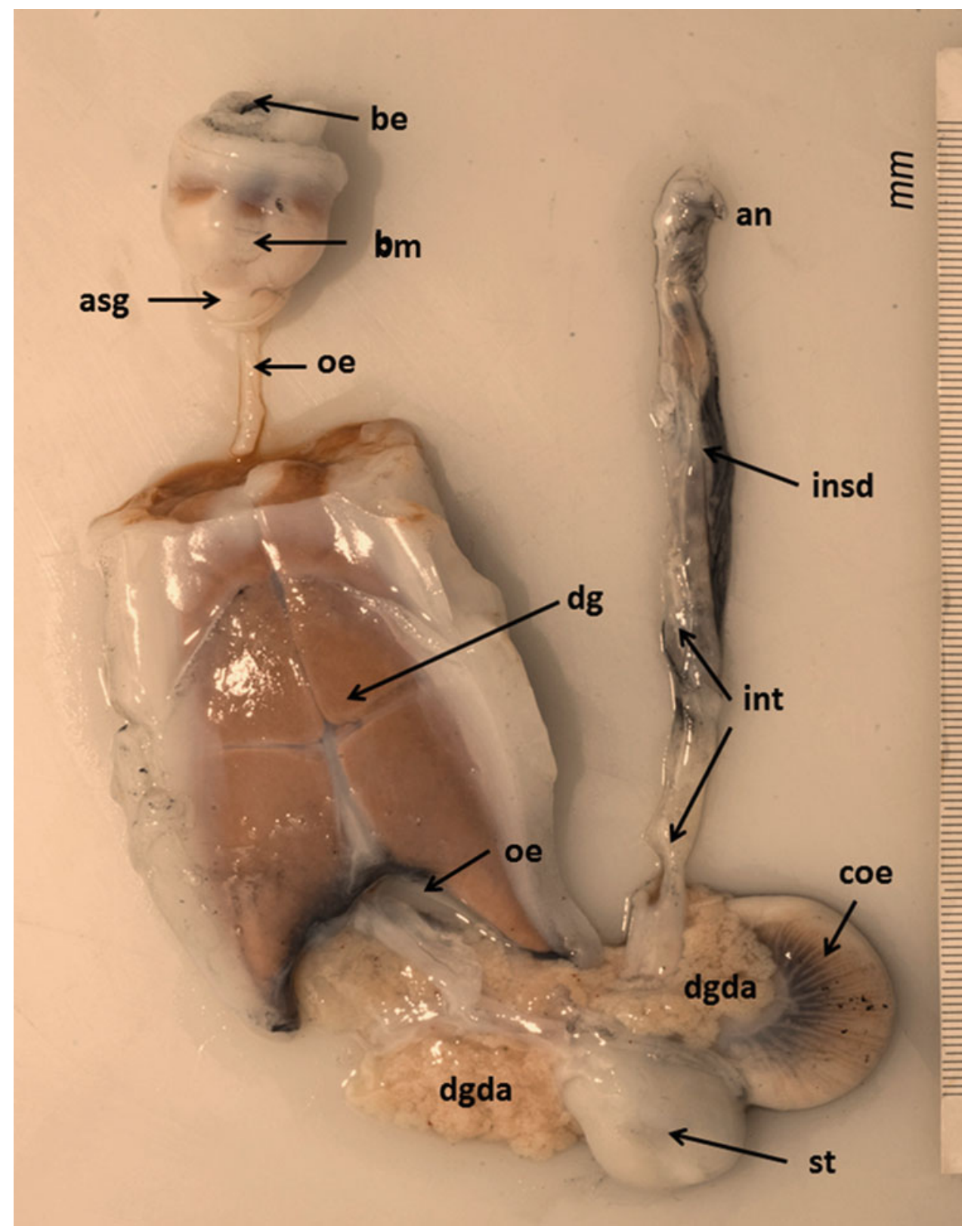

\subsubsection{Digestive System}

The digestive system of the cephalopods (Figs. 3.10, 3.11 and 3.12) opens in the mouth. Located at the base of the arms and tentacles (circumoral appendages), the mouth is the opening of the buccal mass, which contains the beaks, radula, various glands, and the pharynx. Surrounding the mouth, the inner and outer lips possess numerous ridges or papillae. The beaks are two chitinous mandibles bound in powerful muscles. The dorsal beak is referred as "upper" beak, and it inserts within the "lower" beak to tear tissue with a scissors-like cutting action. A pair of glands of the digestive system is associated with the buccal mass, the sublingual and the anterior salivary glands. The function of these glands is poorly known but thought to be primarily in mucous production. The radula, which is a chitinous and ribbon-like band, is placed on the floor of the oral cavity; it contributes to scraping the food in order to fragment it into smaller pieces. The radula can be of various types and its structure varies depending on the group. Many Octopus species are able drilling shells of crustaceans and shells of other mollusks. These drilling activities are carried out by a salivary papilla that lies just below the radula. The papilla is muscular, and its anterior face is covered with very small teeth. It is now possible to say that the salivary papilla can function as an accessory radula. Some cephalopod species (e.g. Spirula spirula) lack of radula. Some cephalopods, 

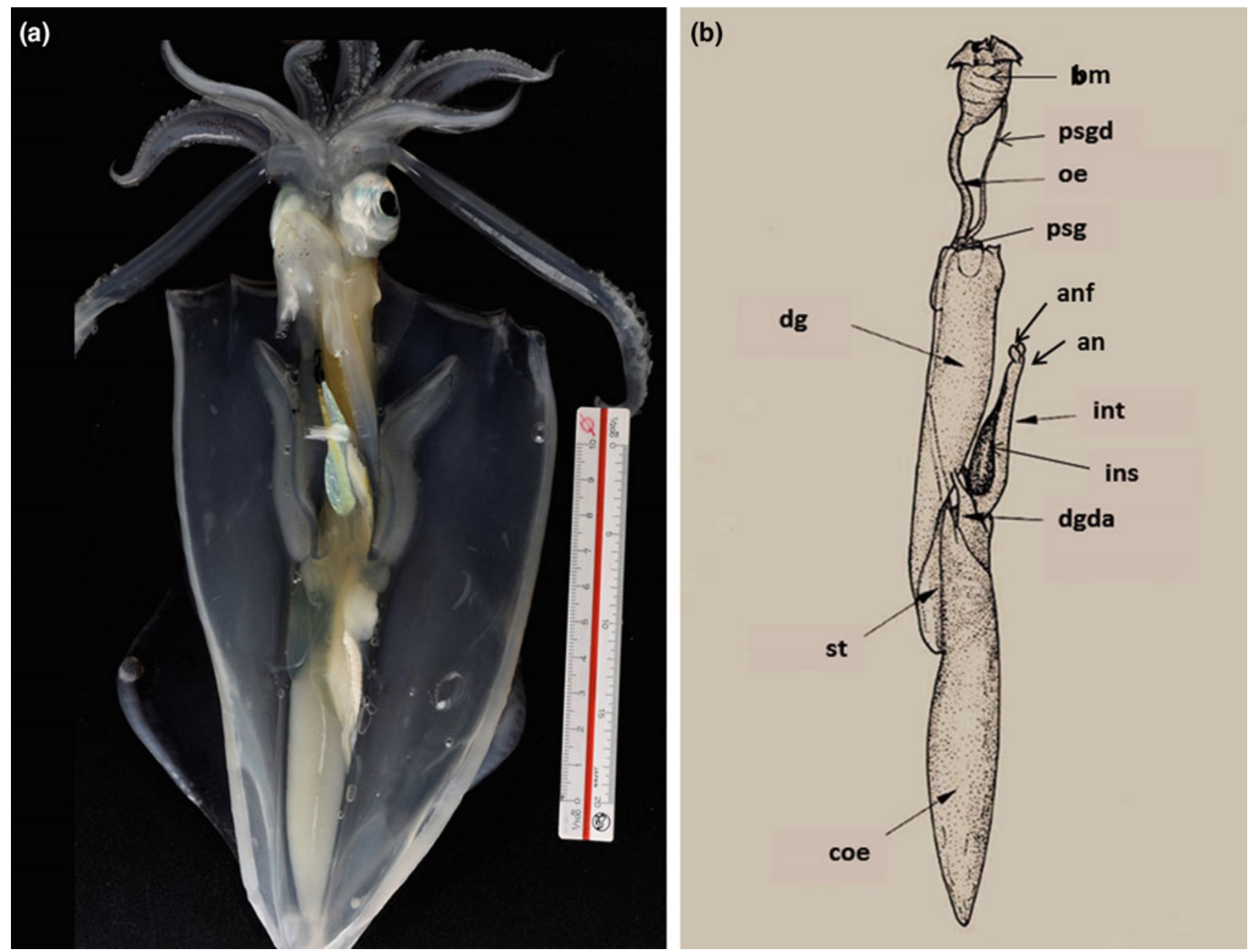

Fig. 3.11 Loligo vulgaris digestive system; a female cut from the ventral side of the mantle: $\mathbf{b}$ diagram showing the main parts of the digestive system; an: anus; anf: anal flaps; bm: buccal mass; cae: caecum; dg: digestive gland; dgda: digestive gland duct appendages;

such as Sepia, Octopus, inject neurotoxins into their prey in order to immobilize them and facilitate their ingestion; these are secreted by the posterior salivary glands. The blue-ringed octopus of the Pacific, Hapalochlaena maculosa, produces toxins that can be deadly to man.

The portion of the digestive tract between the buccal mass and the stomach is the oesophagus. The lumen of the oesophagus is narrow and slightly dilatable, which is because it passes through the brain and cranial cartilage. This is why cephalopods may chop their prey into small pieces with their beaks and then force the pieces down the throat with the radula. Often, a portion of the oesophagus is enlarged to form a crop. This expansion or diverticulum of the oesophagus serves for storing food. It is present in Nautilus and most Octopodiformes. When there is no crop (Fig. 3.12), the oesophagus opens in the stomach. The stomach is a cavity generally lined with cuticular ridges to int: intestine; ins: ink sac; insd: Ink sac duct; oe: oesophagus; psg: posterior salivary glands; psgd: posterior salivary gland duct; st: stomach

grind-up food with the aid of digestive enzymes. The stomach may be greatly expandable in size and serve as a storage area, in species lacking a crop, until food can be fully processed. The caecum is a major organ of this system that is a primary site of absorption. It joins the stomach "upstream" and the intestine "downstream". Present in some Decapodiformes, the caecal sac is a thin-walled posterior portion of the caecum that lacks the internal, ciliated leaflets characteristic of the anterior portion of the caecum (Fig. 3.11b).

The digestive enzymes enter the caecum in the ducts from the digestive gland (Fig. 3.12), which is the primary organ in cephalopods that secretes digestive enzymes. The ducts leading from the digestive gland have outpockets, which are covered with glandular epithelium, and they are called digestive gland duct appendages. Digestive gland is also important in absorption, excretion, and detoxification of heavy metal accumulations. 
Fig. 3.12 Octopus vulgaris digestive system; an: anus; asg: anterior salivary glands; bm: buccal mass; cae: caecum; cr: crop; dg: digestive gland; dgd: digestive gland duct; int: intestine; ins: ink sac; oe: oesophagus; psg: posterior salivary glands; st: stomach

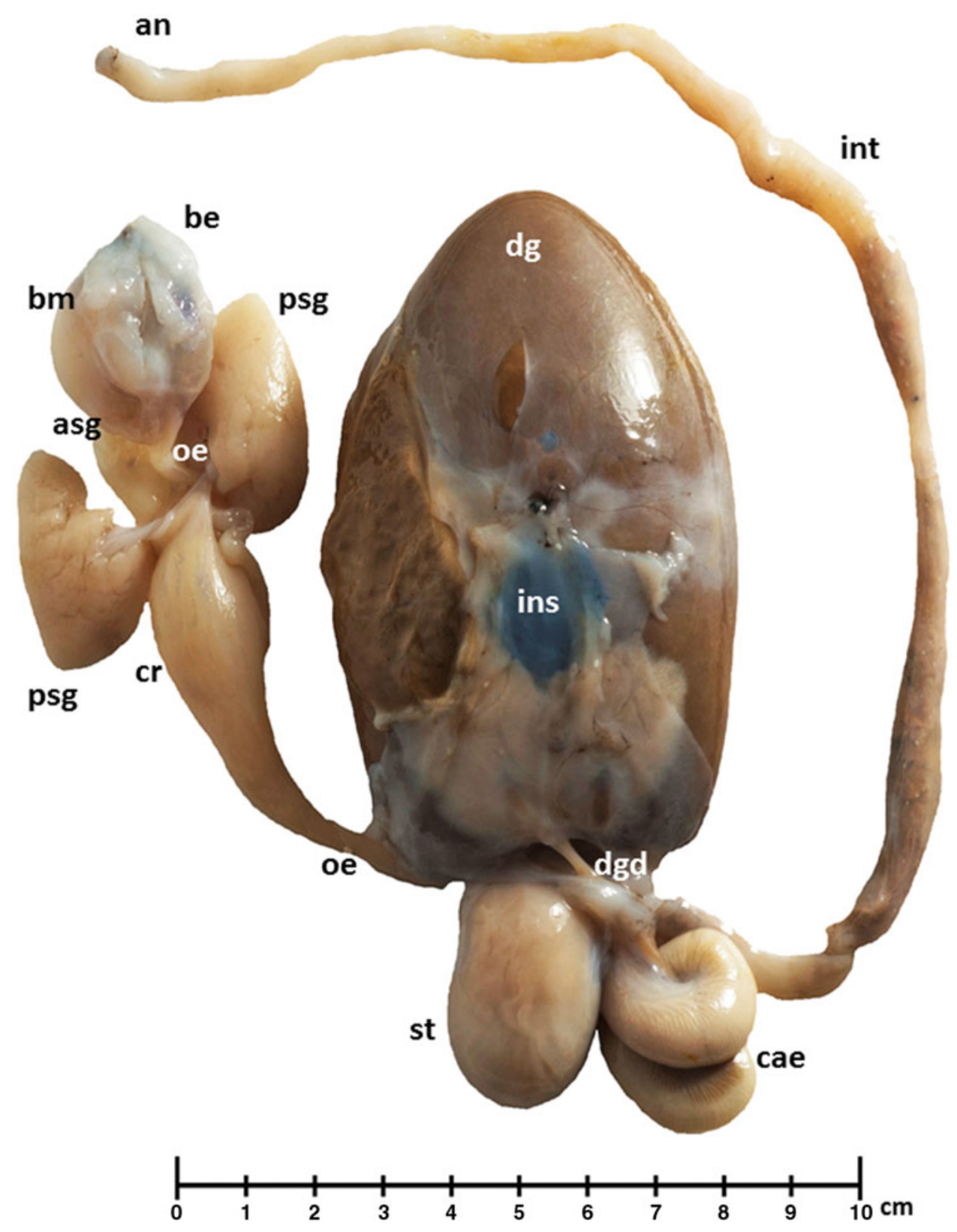

After the caecum begins the intestine, which opens into the anus, situated in the anterior ventral part of the mantle cavity, near the funnel. As a whole, the cephalopod digestive tract has a U-shape. A pair of muscular palps that arise at the sides of the anus in most Coleoidea are called anal flaps (Fig. 3.11).

A notable anatomical feature of the digestive tract of cephalopods is the ink sac. With the exception of nocturnal and very deep-water cephalopods, all Coleoidea which dwell in light conditions have an ink sac. The ink sac is a muscular bag which originated as an extension of the hind gut (Fig. 3.11b). It lies beneath the gut and opens into the anus, into which its contents - almost pure melanin-can be squirted; its proximity to the base of the funnel means that the ink can be distributed by ejected water as the cephalopod uses its jet propulsion. The ejected cloud of melanin forms a lump approximately the size and shape of the cephalopod, fixing the predator's attention while the cephalopod itself makes a hasty escape.

All cephalopods actively catch and eat live prey, and a very range of prey item has been recorded. The diet is probably determined as much by prey availability as predator preference. Hunting is essentially visual; however, chemical cues also probably have a role. Feeding strategies are very different. Once trapped, generally using tentacles or arms, the prey is drawn in towards the mouth which is 
generally paralysed by the saliva of the posterior salivary glands and bitten into the beaks. As above commented, bite-sized of flesh are shallowed. Nevertheless, hard pieces of their prey are also found in the stomach contents, which can be used for preliminary prey's identification. However, to identify prey in cephalopod stomach contents the most accurate is to use molecular techniques. It is well known that cephalopods have high requirements for protein and relatively low requirements for high-quality lipids: the cephalopod diet must consist of over $60 \%$ protein and $4 \%$ lipids.

After ingestion, the already fragmented meal enters in digestive tract. The characteristic fast growth rate of cephalopods (3-10\% body weight $\mathrm{d}^{-1}$ ) sets high requirements for digestion and assimilation. The digestion is a complex process. It starts externally at the prey, where salivary enzymes are injected after perforation by the beaks or salivary papilla. Although the exact biochemical mechanisms in different species are not fully known, it is considered that pre-digestion is probably limited to loosening muscle attachments. Partially digested food is then ingested and enters the crop, in octopus, or goes to the stomach, in cuttlefish and squid, where digestive enzymes from the digestive gland initiate digestion. Enzyme-bound soluble nutrients pass from the crop to the stomach in octopus or directly to the stomach in cuttlefish and squid, where fibrillar proteins and other macromolecules are degraded until a semi-liquid mass of partly digested food (chyme) is formed. The chyme is then separated by the caecum to be transported to the digestive gland or to form faecal pellets. Once in the digestive gland, nutrients are dissolved and absorbed by pinocytosis in the digestive gland cells, where intracellular digestion occurs. This process can take from 4 to $8 \mathrm{~h}$, depending on the size of the meal, animal, and temperature. The high rate of consumption leads to interesting speculations about the fuelling by cannibalism that is relatively frequent in many cephalopods, especially in the long migrations undertaken by many shoaling squid species.

\subsubsection{Excretory System}

Because protein is a major constituent of the cephalopod diet, large amounts of ammonia $\left(\mathrm{NH}_{4}{ }^{+}\right)$are produced as waste. This waste is excreted in solution by several routes. Excretion from the blood system takes place in a well-differentiated renal system surrounding the venous return to the systemic heart. Filtered nitrogenous waste (primary urine) is produced by ultrafiltration from the blood in the pericardial cavity of the branchial hearts, each of which is connected by a narrow canal to the brachial heart appendages (Fig. 3.13). The canal delivers the excreta to a bladder-like renal sac and also resorbs excess water from the filtrate. Several outgrowths of the lateral vena cava (renal appendages) project into the renal sac, continuously inflating and deflating as the branchial hearts beat. This action helps

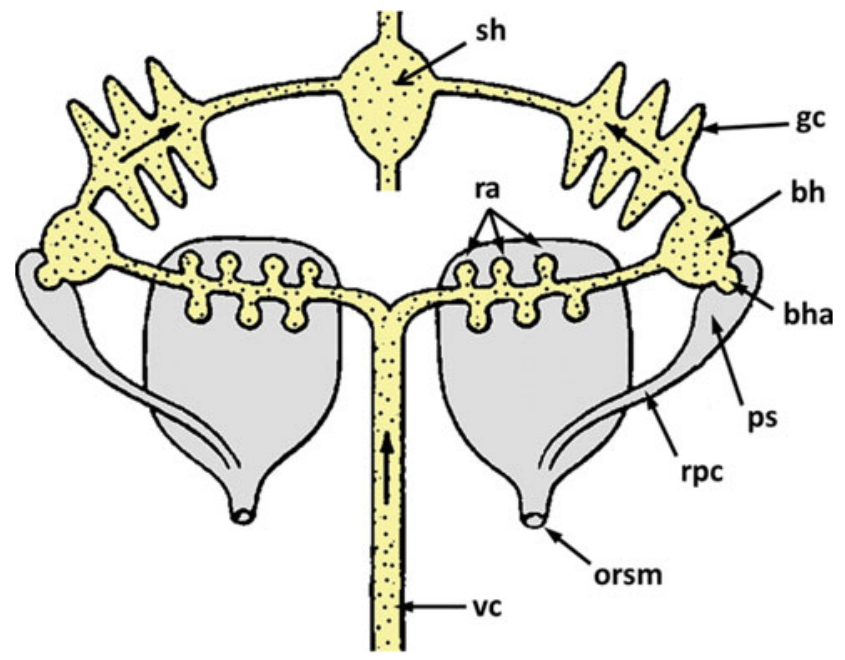

Fig. 3.13 Schematic representation of the excretory (renal) complex and associated circulatory system in Octopus. Arrows show the direction of the blood flux; bh: brachial heart; bha: brachial heart appendages; orsm: opening of renal sac to mantle cavity; ps: pericardical sac; ra: renal appendages; rpc: renopericardial sac; rs: renal sac; sh: systemic heart; vc: vena cava. Modified from Martin AW and Harrison FM. Excretion. In Wilbur and Yonge, C.M. (eds.) Physiology of Mollusca, Vol. II. Academic Press, New York, 1966

to pump the secreted waste into the sacs, to be released into the mantle cavity through a pore (the renal papilla). The main extra-renal organs involved in ammonia excretion are the gills. In this case, the waste is directly excreted from tits epithelium to the seawater. The rate of release is lowest in the shelled cephalopods Nautilus and Sepia as a result of their using nitrogen to fill their shells with gas to increase buoyancy. Other cephalopods use ammonium in a similar way, storing the ions (as ammonium chloride) to reduce their overall density and increase buoyancy. A remarkable feature of the renal system of cephalopods is its infestation by dicyemid mesozoans, which relationship with the host is apparently symbiotic.

\subsubsection{Reproductive System and Reproduction}

Sexes in cephalopods are separate. The reproductive system of the females consists of an ovary, which leads to one or two oviducts, the oviductal gland (single or paired), and the Decapodiformes of the nidamental and accessory nidamental glands (Figs. 3.14 and 3.15) The ovary is located at the back of the mantle cavity, and in it the oocytes are formed. The function of nidamental glands is to produce the outer coat for eggs. The accessory gland has many of the structural features of a secretory organ. The basic structural unit is a tubule composed of a single layer of epithelial cells containing ordered arrays of rough endoplasmic reticulum and a lumenal surface covered with microvilli, cilia, and structural specialization presumed to be involved in secretion. The lumen of each tubule is filled with a dense population of 
Fig. 3.14 Sepia officinalis female reproductive system; an: anus; ang: accessory nidamental glands; bh: branchial heart; fun: funnel; flc: funnel-locking cartilage apparatus; g: gill; ins: ink sac; int: intestine; ng: nidamental glands; oe: oesophagus

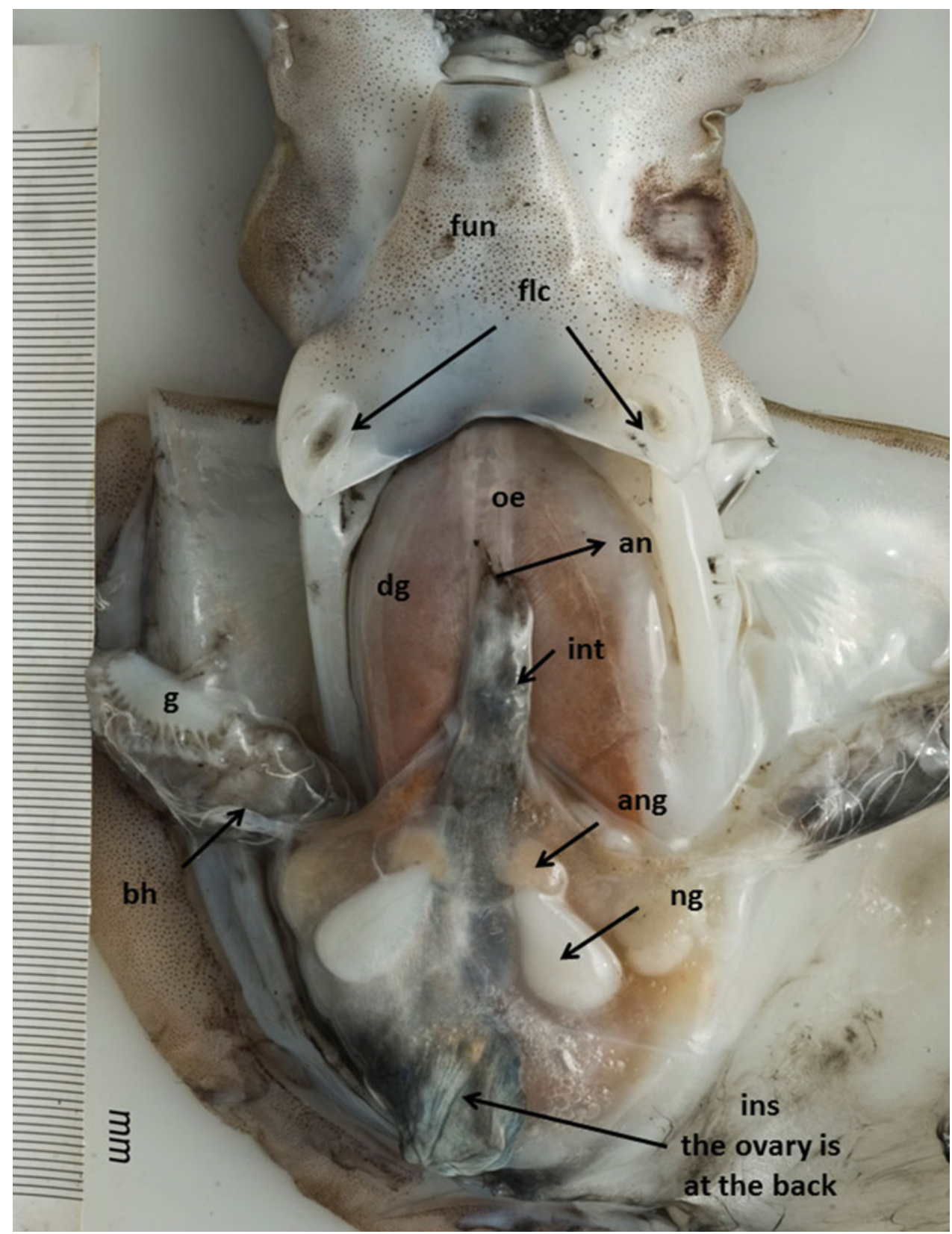

bacteria. During sexual maturation of the squid, the accessory gland changes in colour from white to mottled red (Fig. 3.15a). The accessory gland of the sexually mature squid has a mixture of red, white, and yellow tubules; in each case, the colour of the tubule is due to the bacterial population occupying the tubule. Since the red colour of the gland is due to the pigmentation of the bacteria, the bacteria must be responsive to the sexual state of the host, possible through a change in the nature of the material secreted into the tubule lumen.

Semen can be stored in different parts of the female's body: a sperm receptacle located on the buccal mass, a pouch under the eye, specialized structures found in the skin of some females Decapodiformes or as pockets of the oviducal glands seminal or spermatheca in Octopus species (Fig. 3.16b), a lateral split located in the anterior ventral part of the mantle, within the mantle, etc. The extruded, exploded, evaginated spermatophore/s often in form of round bulb is called spermatangium (pl. spermatangia).

In males, the spermatozoa produced by the testis are packed and surrounded by membranes, forming the spermatophore (Figs. 3.17b and 3.18b). Therefore, a spermatophore is a tubular structure manufactured by male for packaging sperm, capable of holding millions of spermatozoa. A spermatophore is composed by the sperm cord, the cement body, and the ejaculatory apparatus. It is transferred and attached to the 


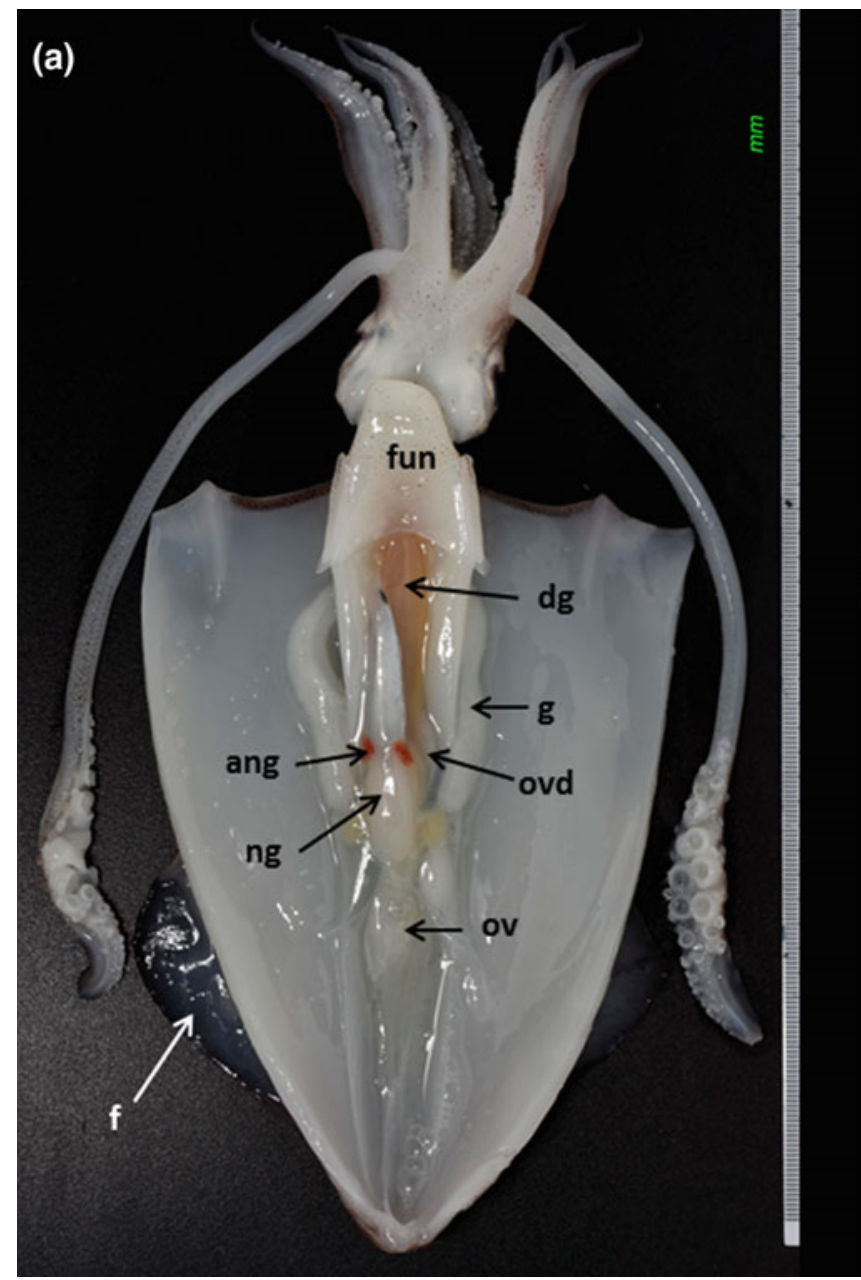

Fig. 3.15 Loligo vulgaris female reproductive system; a general view; b diagram showing main parts; an: anus; ang: accessory nidamental glands; bh: branchial heart; dg: digestive gland; f: fin; fun: funnel; in:

female after fertilization begins, and it forms the spermatangium after the spermatophoric reaction occurs and the spermatophore has everted. After the spermatozoa are formed, they pass to the spermatophoric organ through the vas deferens. The spermatophoric organ is composed by distinct structures different in Decapodiformes (Figs. 3.17 and 3.18) than in Octopodiformes (Fig. 3.18). In Octopus species, it is formed by the seminal vesicle and the prostate, which are the structures engaged in forming the spermatophore sheaths. Ripe spermatophores are stored in the spermatophoric sac or Needham's sac. This sac opens into de mantle cavity or directly into the water through the terminal organ, which by some authors incorrectly denominate penis. Although the terminal organ of some Oegopsida (e.g. Architethis dux) can be extremely long (up to $80 \%$ of mantle length), its functioning is not that of a true penis. This because spermatophore is transferred by the male generally using a modified arm called a hectocotylus. In some species of Octopus, the terminal organ widens into a diverticulum (Fig. 3.19b).

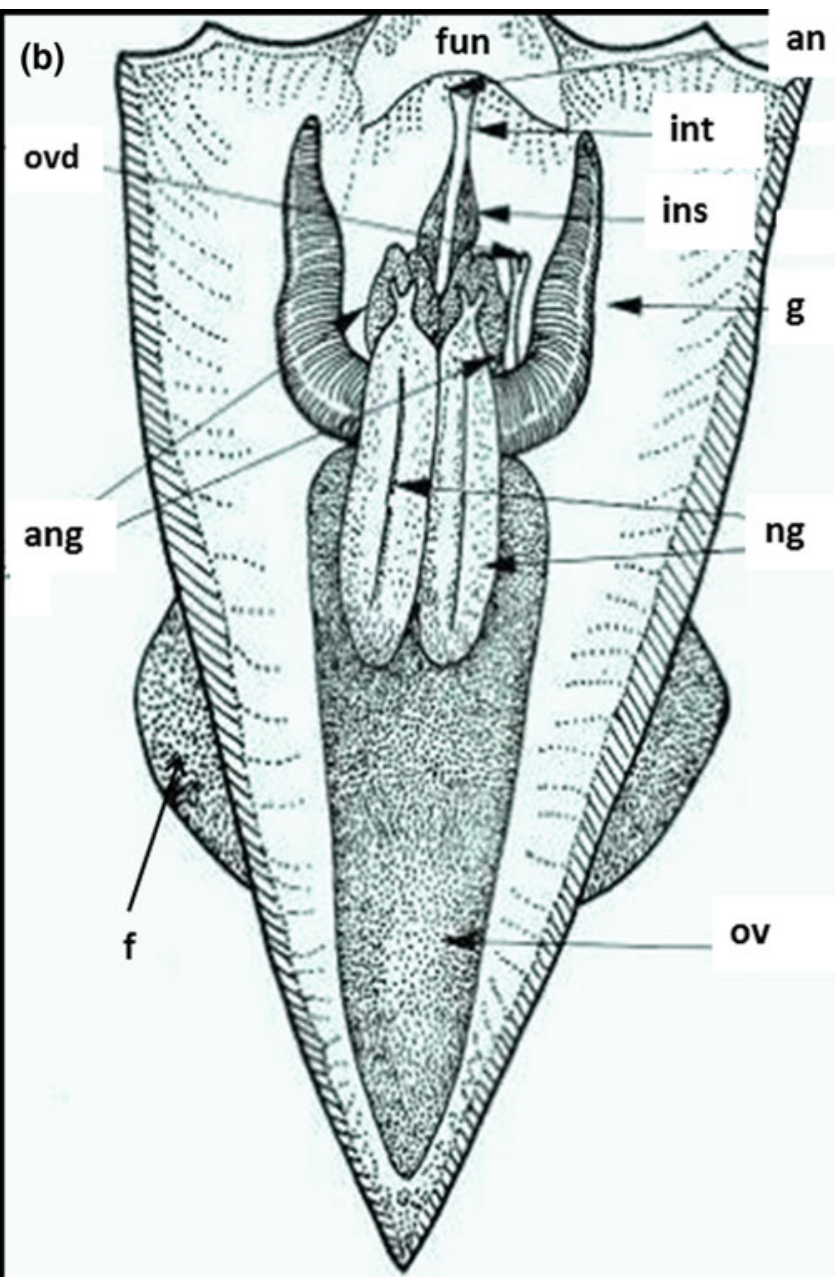

intestine; ins: ink sac; g: gill; int: intestine; ng: nidamental glands; oe: oesophagus; ov: ovary; ovd: oviduct (single in Ommastrephidae, and other Oegopsida are in pair)

Sexual maturation is under the control of hormone(s) released from the small bodies called optic glands located on the optical tract, which connecting optic lobes to the brain. At the onset of sexual maturity, there is a rapid gonad growth, yolk formation in the ova, and ripening of nidamental and accessory glands. In most of the coastal and epipelagic species, reproduction is seasonal and afterwards both males and females die shortly after spawning or after a variable time taking care of the eggs during the embryonic development (e.g. Octopus vulgaris). The causes of the senescence and universal mortality that become after reproductive events are not still understood, although they seem to be related with physical changes in the optic gland and its secretions. Nevertheless, variations of this pattern of monocyclic reproduction and short lifespan are found or suspected in deep-water benthic octopuses and a range of other species.

Cephalopod mating usually includes a courtship that often involves elaborate colour and body pattern changes. Most females then lay large yolky eggs in clusters on the 


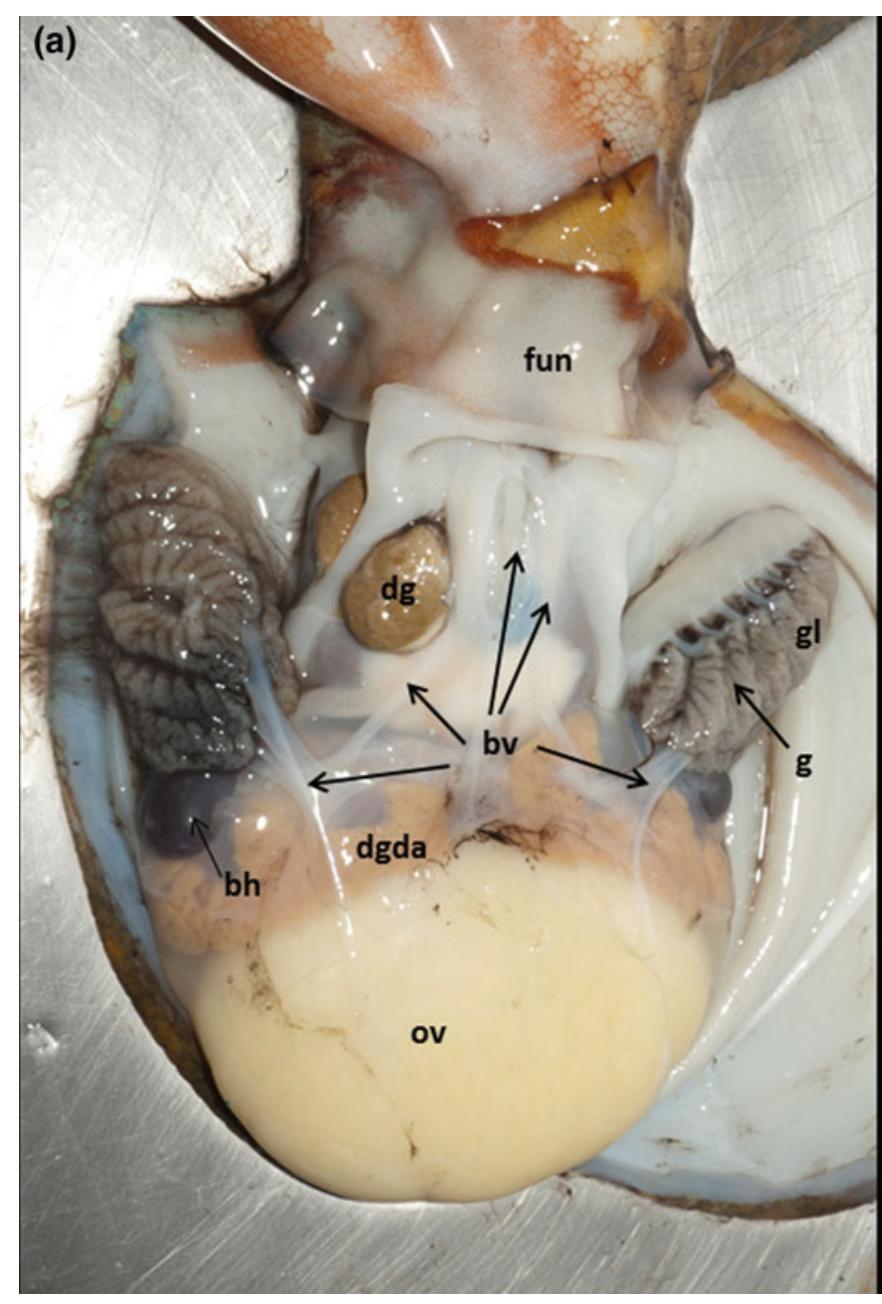

Fig. 3.16 Octopus vulgaris female reproductive system; a general view; b diagram showing main parts and a section of the oviducal glands; c main parts; bh: branchial heart; bv: blood vessels; fun: funnel;

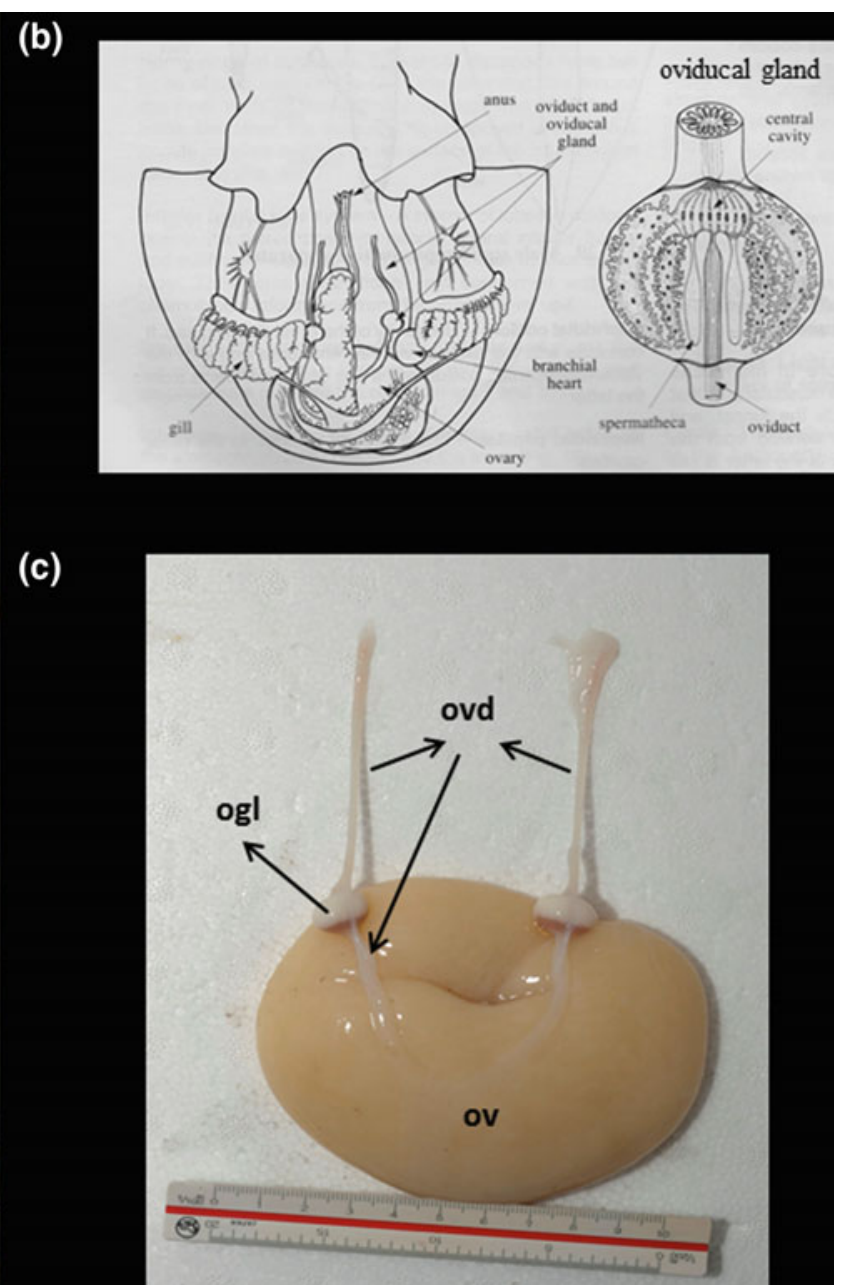

dg: digestive gland; g: gill; gl: gill lamellae; ov: ovary; ovd: oviducts; ogl: oviducal gland

wider range of possibilities than vision. The studies of a few nearshore species have revealed complex behaviour and remarkable capacity for learning. The kind of information collected by these sense organs, the nature of its effectors or motor apparatus, and the organization of the brain are the main factors on which its behaviour depends (Hanlon and Messenger 1996). In the previous sections, the main effectors or body organs that carry out, or "effect", the responses an animal makes to a stimulus (e.g. arms, tentacles, suckers, fins, chromatophores organs, reflecting cells, photophores, and ink sac) were show. In this section, information about the sense organs is given. The following one will deal with the organization of the brain and the peripheral nervous system, which in these organisms is very important. Table 3.1 summarizes main information on the sense organs of these peculiar marine molluscs.

\subsubsection{Sensory Systems}

Cephalopods (excluding Nautilus) are predatory, agile, swift-moving and, except few exceptions, highly visual animals that can see well under highly varying light conditions. Nevertheless, cephalopod sensory systems cover a 


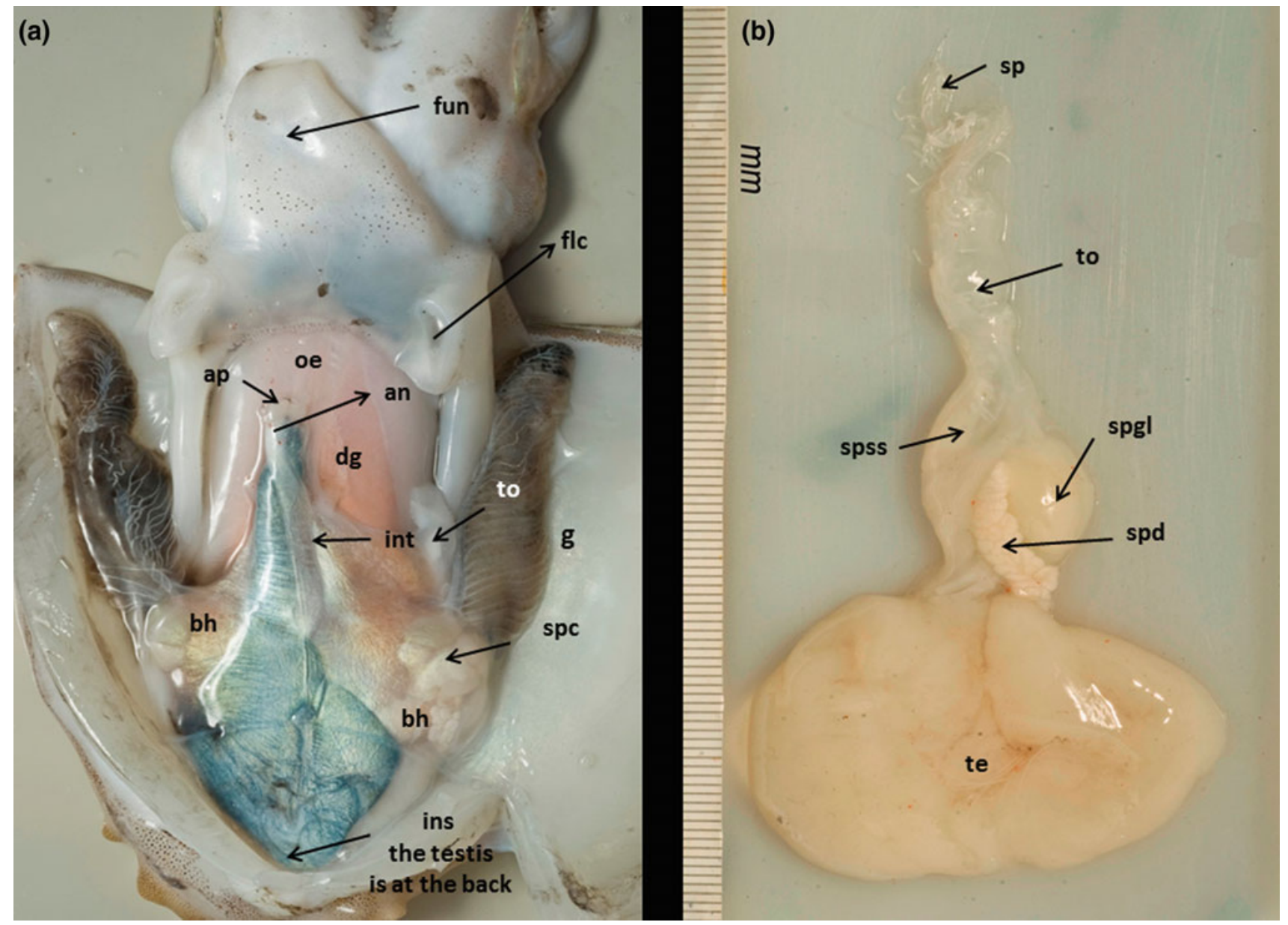

Fig. 3.17 Sepia officinalis male reproductive system; a general view; b main parts; an: anus; anf: anal flaps; bh: branchial heart; fun: funnel; flc: funnel-locking cartilage apparatus; g: gill; ins: ink sac; int: intestine;

\subsubsection{Nervous System}

The cephalopod nervous system is divided into a central and a peripheral part. The central part includes the brain proper and the optic lobes; the large peripheral part includes the nervous system of the body and of the arms.

The brain is protected by a cartilaginous skull or cephalic cartilage. It is arranged around the oesophagus. There is a supra-oesophageal and a sub-oesophageal part, and they are laterally connected by a part that may be considered as peri-oesophageal. Each of these parts is further subdivided into a varying number of lobes. In octopods and decapods, 25 major lobes have been described; however, some are further subdivided, giving a total number of 37 and 38 lobes, respectively (Fig. 3.20). It is beyond the aim of this section to describe the structures and possible functions of all the 38 brain lobes. For and excellent and comprehensive descriptions and reviews, see Nixon and Young (2003). Table 3.2 shows the principal information about the common octopus oe: oesophagus; sp: spermatophores; spgl: spermatophoric gland; spss: spermatophoric sac or Needham's sac; te: testis; to: terminal organ ("penis")

(Octopus vulgaris) brain, which is the well-known central nervous system among cephalopods.

The peripheral nervous system contains twice as many nerve cells (350 million) as the central nervous system. All peripheral ganglia are lower motor centres. The largest part of the peripheral nervous system is the five brachial nerve cords; each has one large axial cord, four much smaller peripheral intramuscular cords, and as many brachial ganglia as the arm has suckers; in addition, each sucker has its own small sucker ganglion. Most of the neurons in the brachial and sucker ganglia are (lower) motor neurons that drive the muscles of the suckers, but they also analyse chemo- and mechanosensory as well as propiosensory inputs.

The most well known of the peripheral ganglia are the stellate ganglia on the inside of the mantle. These ganglia are lower motor centres for the movement of the mantle. They house the giant synapse and give rise to the stellate nerves. The giant fibre system is present in Decapodiformes only 


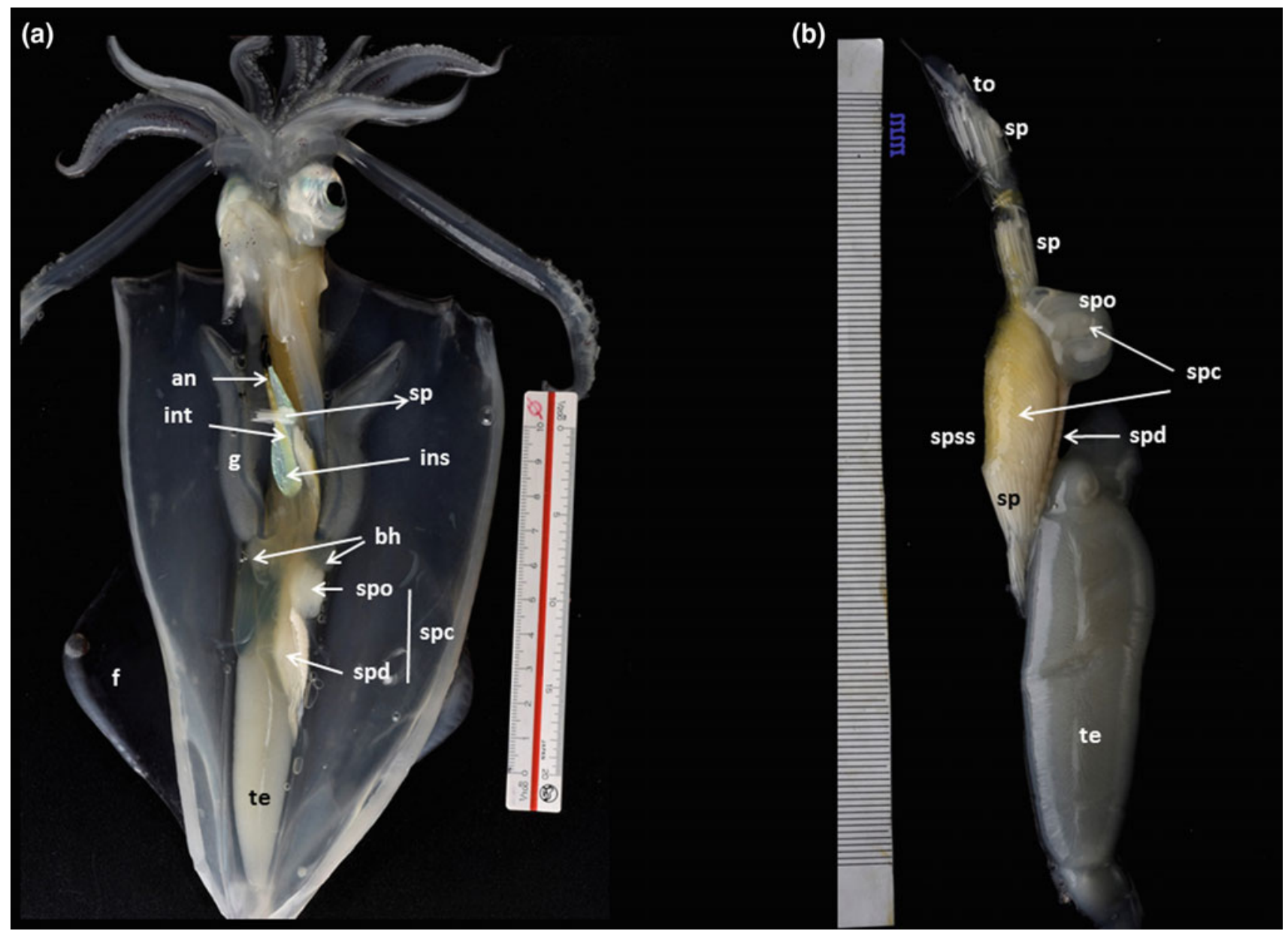

Fig. 3.18 Loligo vulgaris male reproductive system; a general view; b main parts; an: anus; anf: anal flaps; bh: branchial heart; f: fin; fun: funnel; g: gill; ins: ink sac; int: intestine; sp: spermatophores; spc:

and is composed of a chain of three giant nerve cells on each side. The first-order giant cell lies in the ventral magnocellular lobe; its axon runs to the pallio-visceral lobe where it crosses to the contralateral side, forming a fusion (Loligo) or a synapse (Sepia) at the chiasma with its contralateral peer. From there, the second-order giant cell runs to the stellate ganglion. There, it connects via the giant synapse to the third-order giant cell (s), which drives the mantle musculature. The main function of the giant fibre system is fast escape jetting.

Other peripheral ganglia are: the inferior buccal and subradular ganglia, which control the buccal and the radula movements; the large gastric ganglion, which innervates the crop, stomach, caecum, and intestines; the fusiform, cardiac and auricular ganglia, which innervate the vena cava and the gill and systemic hearts; and the branchial (or gill) ganglia, which innervate the muscles of the gill lamellae. spermatophoric complex; spo: spermatophoric organ or gland; spss: spermatophoric sac or Needham's sac; te: testis; to: terminal organ

\subsection{Post-mortem Examination and Recognition of Tissues Abnormalities}

\subsubsection{Necropsy and Post-mortem Examination: Preliminary Remarks}

Although there are some documents on how to necropsy some species of cephalopods, to date there was no attempt to produce a general guide. The information used to perform this section has three origins: (i) exiting partial documents (e.g. dissection technique to Sepia officinalis by A.V Sykes 2016); (ii) information of the excellent atlas on Salmonid diseases by Bruno et al. (2013), and (iii) our own experience.

Post-mortem examination or necropsy is the procedure of examining a body with the objective of assessing the lesions 


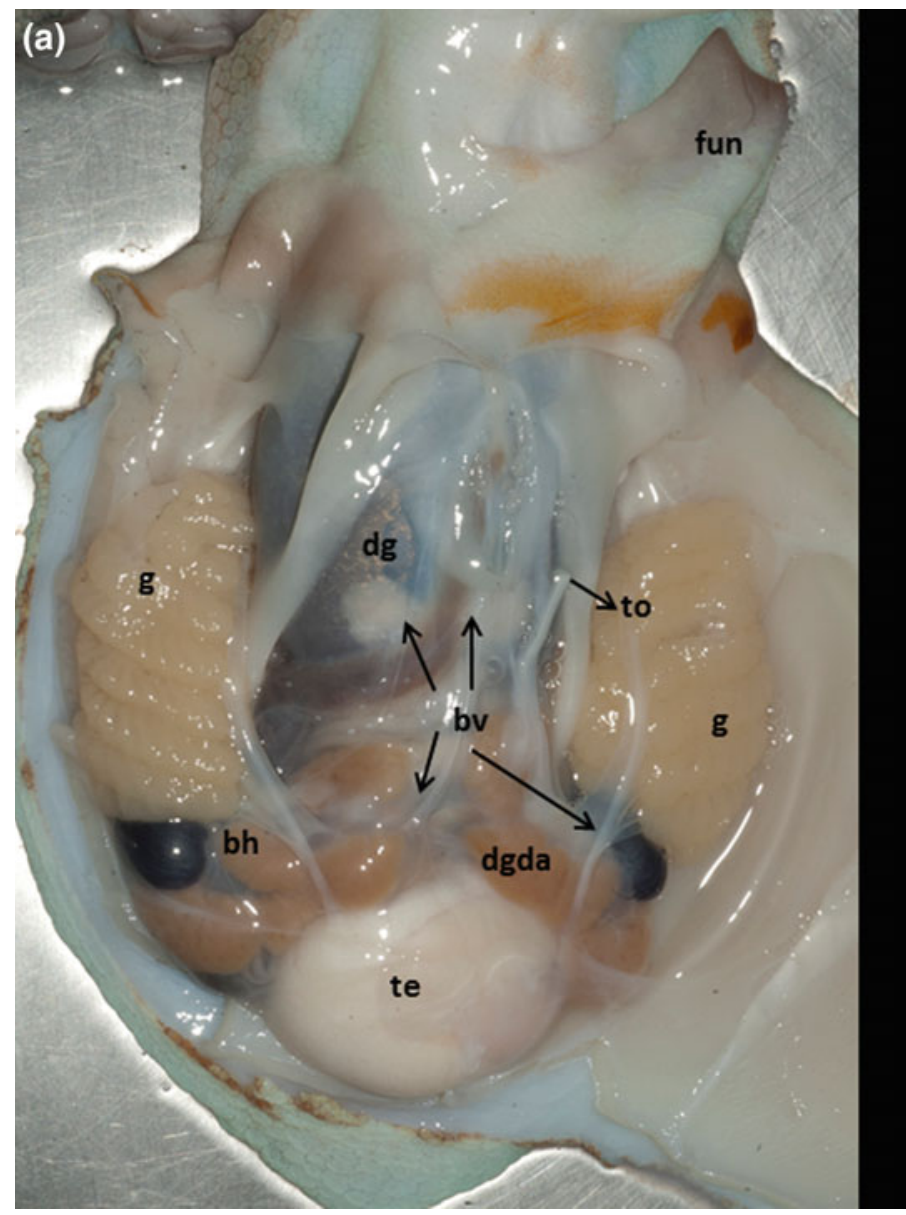

(b)

Fig. 3.19 Octopus vulgaris male reproductive system; a general view; b main parts; an: anus; bh: branchial heart; bv: blood vessels; d: diverticulum of the terminal organ; fun: funnel; g: gill; sp:

present and the cause of death. This is achieved through a systematic approach and observation of external and internal structures, organs or tissues, assisted by the collection of samples for further analysis.

Any cephalopod sample can have two origins: wild or cultivated. As the industrial culture of these organisms is underdeveloped, it is quite unlikely that the sample comes from a farm. However, the sample could come from individuals kept in confinement in the laboratories. In order to undertake an appropriate cephalopod health assessment when the specimen is alive in their habitat, it is very useful to have data of the main parameters of the water mass (locality, water temperature, $\mathrm{pH}$, salinity, and chemical and physical conditions) in which the animal has lived, as well as some characteristics of its habitat. Under farming or rearing conditions, information on changes in the standard cephalopod behaviour should be noted. Moreover, management practices as well as diet and feeding response also become of particular relevance. spermatophores; spc: spermatophoric complex; spgl: spermatophoric gland; spsg: spermatophoric sac gland; spss: spermatophoric or Needham's sac; te: testis; to: terminal organ

When it comes to examining a group of individuals belonging to a more or less numerous population or group, records of the number (or the best possible estimation) of affected individuals within the population should be ascertained. This data, along with a detailed history of daily and total mortality, taking into account the size, sex, maturity stage, age (when possible), and origin of the stock, will allow establishing: (i) the morbidity rate and (ii) the pattern of the spread of the disease or abnormality observed.

Normally, this preliminary diagnosis made from wild animals or kept in aquaria is not definitive. This emphasizes the need of the necropsy. The description provided in this chapter describes the procedures of necropsy with particular reference to obtaining adequate samples of the most common tissues collected for histological examination. This is on the understanding that during necropsy, other samples will also be taken, e.g. for microbiological analysis, as well as blood or tissue samples for immunological or molecular studies, analyses of heavy metals concentrations, or 
Table 3.1 Cephalopod sensory organs (modified from Nixon and Young 2003)

\begin{tabular}{|c|c|c|c|}
\hline Eyes & $\begin{array}{l}\text { Larger posterior chamber, lens, iris, retina, } \\
\text { choroid, sclera, and argentea. } \\
\text { Extraocular eye muscles. } \\
\text { Similarity to vertebrate eyes }\end{array}$ & $\begin{array}{l}\text { Rabdomeric type; rabdomera instead } \\
\text { rod and cone cells in the retina. } \\
\text { Generally a single visual pigment: } \\
\text { rhodopsin. Most species blind to } \\
\text { colours }\end{array}$ & $\begin{array}{l}\text { Excellent visual ability an } \\
\text { acuity. } \\
\text { Polarization sensitivity }\end{array}$ \\
\hline $\begin{array}{l}\text { Photosensitive } \\
\text { vesicles }\end{array}$ & Head and mantle & $\begin{array}{l}\text { Compare sunlight with the one emitted } \\
\text { by their own photophores themselves }\end{array}$ & $\begin{array}{l}\text { Downwelling } \\
\text { Camouflage }\end{array}$ \\
\hline Statocysts & $\begin{array}{l}\text { Paired organs in the skull. } \\
\text { System 1: Macula-statolith-statoconia } \\
\text { System 2: Cresta-cupula }\end{array}$ & $\begin{array}{l}\text { Direction of gravity and linear } \\
\text { acceleration. } \\
\text { Countershading reflexes. } \\
\text { Rotational acceleration }\end{array}$ & $\begin{array}{l}\text { Balance and equilibrium. } \\
\text { Infrasound. } \\
\text { Countershading }\end{array}$ \\
\hline "Lateral lines" & $\begin{array}{l}\text { Mechanoreceptors or epidermis lines in } \\
\text { different regions of the body }\end{array}$ & $\begin{array}{l}\text { Detection of the impact of waves of } \\
\text { pressure of the surrounding water }\end{array}$ & Detection in the dark \\
\hline Suckers & $\begin{array}{l}\text { Decapodiformes: Cuttlefishes and squids, } \\
\text { with corneal rings } \\
\text { Octopodiformes: octopuses; no corneal rings }\end{array}$ & $\begin{array}{l}\text { Chemoreceptors. } \\
\text { Mechanoreceptors. } \\
\text { Propioreceptors }\end{array}$ & $\begin{array}{l}\text { Taste, smell, touch, pressure, } \\
\text { and position of the own body } \\
\text { and limbs in space }\end{array}$ \\
\hline $\begin{array}{l}\text { Olfactory } \\
\text { organs }\end{array}$ & $\begin{array}{l}\text { In Coleoidea: a couple of small holes, one } \\
\text { each side of the head under the eyes and near } \\
\text { the edge of the mantle. } \\
\text { Epithelial structures (rinophores) }\end{array}$ & Chemoreceptors & Smell \\
\hline Nociceptors & In the skin, muscles, and viscera & $\begin{array}{l}\text { They detect changes at chemical, } \\
\text { thermal, and mechanical level, } \\
\text { associated with cellular damage }\end{array}$ & Pain \\
\hline
\end{tabular}

statocysts to study of the damaging effects of the impacts of artificial sound sources. However, these procedures will not be covered or discussed in detail in this chapter.

\subsubsection{Sample Size}

The number of specimens sampled for a health assessment will vary according to the objectives of the study. For example, certification of freedom of a notifiable disease generally follows the guidelines from the Office International des Epizooties (OIE).

To obtain a 95-98\% probability of detecting at least one infected cephalopod in a clinically healthy population, this translates to a minimum of 30 individuals. Conversely, for disease investigations, five to ten individuals showing abnormal behaviour or the characteristic signs of the condition will be adequate for necropsy. Despite these specifications, many times one will have to work with a single or few individuals.

Cuttlefishes, squids, or octopuses removed alive for examination should be placed into a smaller container where further observations can be made before any procedure or the removal of tissues or body fluids. The animal should be sacrificed (euthanized) by a humane method.

\subsubsection{Euthanasia}

The inclusion of "all live cephalopods" in Directive 2010/63/EU that regulates the use of animals for scientific purposes (European Parliament and Council of the European Union 2010) entails the identification of humane methods for killing, which is a particular challenge for neuroscience, as pointed out by the comprehensive paper of Fiorito et al. (2014).

The first point that should be taking into account is that a general anaesthesia is required for performing surgical procedures followed by recovery. Over the last century, a diverse range of substances has been used to induce general anaesthesia in cephalopods (see Andrews et al. 2013 for a review). Following Andrews et al. (2013), criteria for assessment of general anaesthesia in cephalopods include: (1) depression of ventilation and in some cases cessation, probably accompanied by reduced cardiac activity; (2) decrease in chromatophore tone (indicative of reduced drive to or from the sub-oesophageal chromatophore lobes); (3) reduced arm activity, tone, and sucker adhesion (particularly octopus); (4) loss of normal posture and righting reflex; (5) reduced or absent response to a noxious stimulus.

The Directive requires that if, for a justified reason (e.g. at the end of project, to obtain tissue for an in vitro study, 


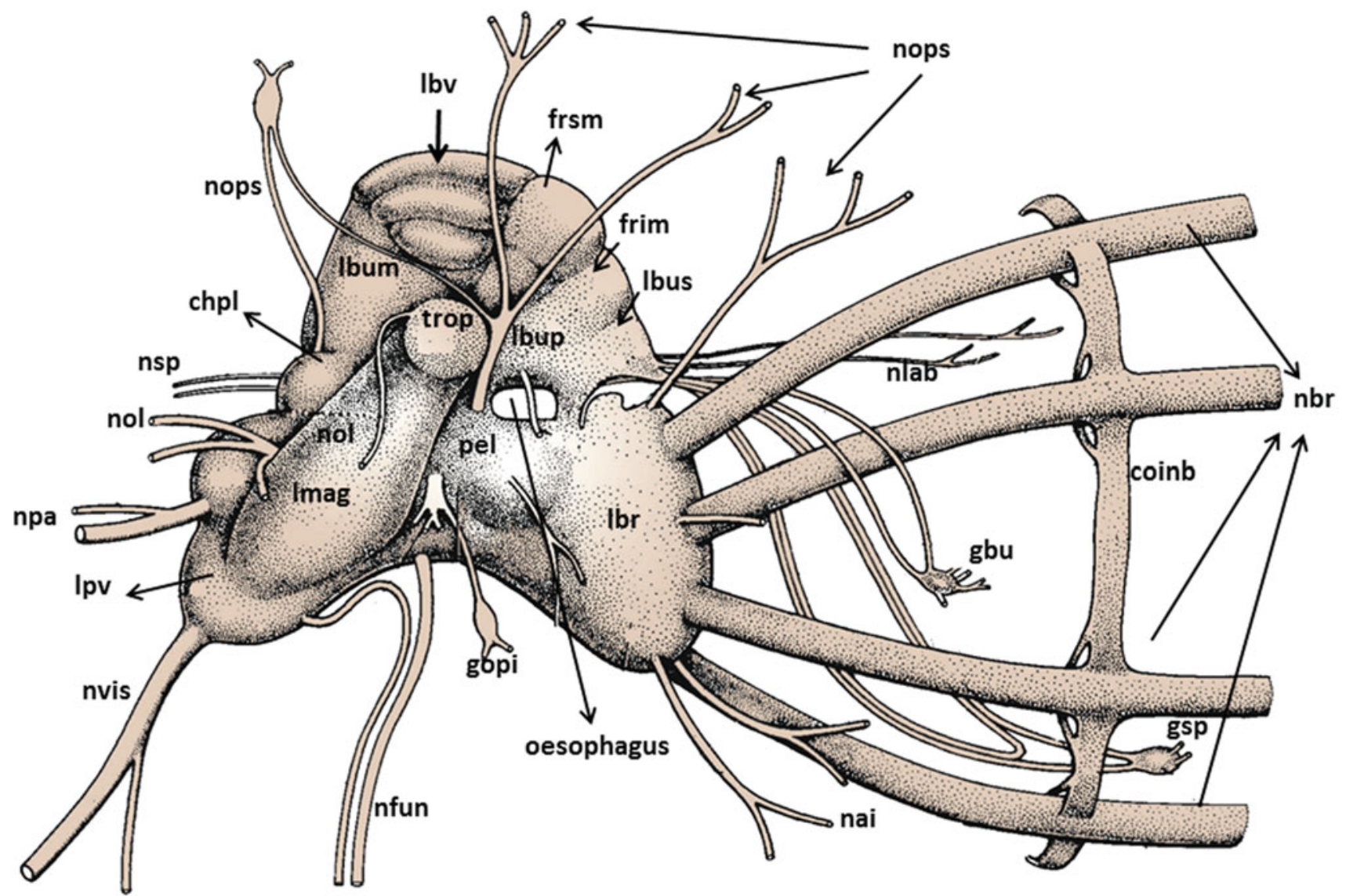

Fig. 3.20 Drawing of reconstruction of the Octopus vulgaris central nervous system (brain) drawn from serial sections; see from the right side (Young 1971); chpl: chromatophoric lobe; coinb: interbrachial commissure; frim: median inferior frontal lobe; frsm: median superior frontal lobe; gbu: buccal ganglia; gopi: inferior optic ganglia; gsp: posterior salivary ganglia; lbra: brachial lobe; lbum: median buccal

because a humane end point is reached), it is necessary to kill an animal, it must be done "with the minimum of pain, suffering, and distress" (Article 6). The methods to euthanize a specimen can be summarized in two main categories: (1) mechanical methods (cutting between the eyes to destroy the brain and/or decapitation); (2) chemical methods-(a) cooling: cool water containing $2 \%$ ethanol; (b) magnesium chloride $\mathrm{MgCl}_{2}$ alone or in combination with eugenol; (c) chloroform; and (d) carbon dioxide. All current techniques use immersion in sea water containing the anaesthetic agent. Time of exposition will depend on the species and size of the cephalopod.

Based upon current evidence, the following method is proposed for humanely killing cephalopods such as Sepia officinalis, Dorytheuthis pealei, Octopus vulgaris, and Eledone cirrhosa: at least 15 min immersion in $\mathrm{MgCl}_{2}$ (with a rising concentration [optimal rates remain to be determined], lobe; lbup: posterior buccal lobe; lbus: superior buccal lobe; lbv: vertical lobe; lmag: magnocellular lobe; lpv: pallio-visceral lobe; nbr: brachial nerve; nlab: labial nerves; nops: superior posterior ophthalmic nerves; nol: olfactory nerve; nsp: posterior salivary nerve; nvis: visceral nerve; nfun: funnel nerve; pel: lateral pedal lobe; trop: optic tract

ending with a final concentration of at least $3.5 \%$ in the chamber used for humane killing), possibly enhanced by using a chilled solution or with the clove oil active constituent eugenol, followed by immediate mechanical destruction of the brain (Andrews et al. 2013).

It must be emphasized that the above are initial proposals, and it is likely that methods will need to be refined, possibly with the identification of species-specific protocols.

Annex IV of the Directive includes methods for confirmation of death, and these are discussed in relation to cephalopods in the paper of Andrews et al. It should also be noted that the requirement for humane killing also applies to hatchlings. In this last case, killing by direct immersion in fixative would not now be considered acceptable in the EU, although it might be possible to obtain permission to use this as a method if it could be justified to the National Citizens Alliance (NCA). 
Table 3.2 Number of cells and a summary of main functions of the principal lobes of the Octopus vulgaris brain (modified from Nixon and Young 2003)

\begin{tabular}{|c|c|c|}
\hline Masses and lobes & No of cells & Main functions \\
\hline Optics lobes & 128940000 & $\begin{array}{l}\text { Analysers of the visual input and regulate visual behaviour } \\
\text { They initiate the programs by which the higher motor centres } \\
\text { (the basal lobes) produce the various motor activities of the } \\
\text { animal } \\
\text { Centres for simple visual discrimination learning and also involved } \\
\text { in the expression of the various chromatic components }\end{array}$ \\
\hline $\begin{array}{l}\text { Sub-oesophageal mass } \\
\text { Palliovisceral } \\
\text { Chromatophore } \\
\text { Vasomotor } \\
\text { Brachial } \\
\text { Pedal }\end{array}$ & $\begin{array}{r}108000 \\
526000 \\
1307000 \\
341000 \\
241000\end{array}$ & $\begin{array}{l}\text { Motor centres involves in most action of the animal } \\
\text { Control of muscular activity of the mantle and viscera } \\
\text { Management of the chromatophoric's muscles } \\
\text { Control of the musculature of blood vessels } \\
\text { Actions of the arms and tentacles } \\
\text { Idem }\end{array}$ \\
\hline $\begin{array}{l}\text { Supra-oesophageal mass } \\
\text { Vertical } \\
\text { Subvertical } \\
\text { Frontal Superior } \\
\quad \text { Inferior } \\
\text { Subfrontal } \\
\text { Subpedunculate } \\
\text { Basal }\end{array}$ & $\begin{array}{r}25066000 \\
810000 \\
1854000 \\
1085000 \\
5308000 \\
144000\end{array}$ & $\begin{array}{l}\text { Lobes linked for the management of exploratory actions, learning } \\
\text { and short and long term memories } \\
\text { In addition, they are closely related to the functional system } \\
\text { related to the chemotactile stimuli coming from the suckers } \\
\text { and the mouth, as well as visual stimuli coming from the eyes }\end{array}$ \\
\hline $\begin{array}{l}\text { anterior } \\
\text { dorsal } \\
\text { lateral } \\
\text { median } \\
\text { Buccal superior } \\
\text { Peduncle } \\
\text { Olfactory }\end{array}$ & $\begin{array}{r}380000 \\
1796000 \\
127000 \\
245000 \\
150000 \\
142000 \\
136000\end{array}$ & $\begin{array}{l}\text { Control of posture and movements of head and eyes } \\
\text { Control of defence and avoidance strategies } \\
\text { Control of the chromatophores and the muscles in the skin } \\
\text { Control of swimming and respiration } \\
\text { Motor control of feeding } \\
\text { Coordinate motor activity, colour changes and ink-injection } \\
\text { Control of muscles of olfactory organs }\end{array}$ \\
\hline $\begin{array}{l}\text { Peri-oesophageal mass } \\
\text { Magnocellular lobe }\end{array}$ & 581000 & $\begin{array}{l}\text { This lobe is particularly involved in defence and fast escape } \\
\text { reactions } \\
\text { The giant fibre system originates there }\end{array}$ \\
\hline
\end{tabular}

\subsubsection{Necropsy Procedure}

\subsubsection{External Examination}

The first operation to be performed is to try to eliminate the water that has remained in the specimen's paleal cavity. The most convenient is to use an absorbent paper. The specimen should be placed in a tray that prevents further contamination and which allows performing the work. Above the tray, and below the animal, an absorbent paper to remove excess water should be placed. It is ideally maintained the specimen at cool temperatures throughout the necropsy, which can be achieved by placing ice below the tray.

The most appropriate is to completely extend (arms and tentacles included) the specimen in the tray and begin the inspection by its dorsal face, the opposite of where the funnel is located. The mantle, head, and arms should be carefully examined. Any deviation from normality for the species throughout the process of the post-mortem examination should be recorded in a notebook. The provision of a reference to the relative position of the abnormality or the sample taken is an essential part of the report. When the exam of the dorsal region is finished, the same should be done with the ventral one, turning the specimen over. A thorough check of the entire body external surface (which should be done under a dissecting microscope a when necessary) is anatomical anomalies, such as the integrity of the skin and fins, changes of normal pigmentation for the species, loss of arms and/or tentacles, bifurcation of the arms, anomalies in the copulatory arms, regeneration of arms and/or suckers, erosion, ulcers, grossly visible parasites, evidence of cuttlebone deformity (Sepia) or muscle atrophy, but, above all, tumorous-like conditions in the arms, head, eyes, and/or the mantle. Keep in mind that in cephalopods it will not be possible to denote haemorrhages, since their blood is bluish white. The mouth and the oral cavity should be examined recording the presence of any possible, vesicles, parasites, or abnormality associated with these structures. Samples of skin and mucous can be taken for 
immediate analysis. Carefully remove a small piece approximately $1 \mathrm{~cm}^{3}$ and place immediately in fixative such as $10 \%$ buffered formal saline. A gross examination of the eyes should include reference to corneal opacity, cataract, or exophthalmia which, although not necessarily pathognomonic, can indicate a minor infection or a sign of a more serious condition. To remove the eye carefully dissect the skin around the orbit using small curved scissors or a scalpel until sufficient tissue is available to grip with forceps. Pull the eye forwards in order to expose the associated muscles and then cut free the entire eye ball, but it is not advisable to try to extract the optic lobes or the ocular nerves, which should be done when working with the brain. Eye fixation can be made using Carnoy's solution instead of formalin. However, when the main interest is parasitological examination, this will usually require fixation in $70 \%$ alcohol.

For the purpose of histological examination, specimens of this small size can be preserved whole, but making a cut in the ventral region that allows the fixative to penetrate within the mantle cavity and guarantee proper fixation. For larger specimens, fresh samples of tissues (mainly skin ones) or body fluids can also be taken for initial in situ analysis, but for histological examination tissues need to be dissected using scalpel, scissors, and forceps. If the animal has a rigid internal shell (cuttlebone or gladius), it is not convenient to remove it, because that preserves the rigidity of the body and the internal organs in their natural position.

\subsubsection{Internal Examination}

To access the internal organs the mantle or paleal cavity is opened. There are several ways to approach dissection, however, the choice must prevent or reduce the likelihood of the process introducing artefacts, damaging tissues, compressing, cutting, moving, or displacing organs as well as avoiding the risk of contamination. Place the animal with the ventral side facing towards you; gently press the both lateral sides of the mantle to open a cavity; then, use the scissors with the blunted side facing the inside of the mantle to perform a cut along the mid-ventral line of the mantle that reaches its end the cut can be also performed laterally (as shown in Fig. 14 to Sepia officinalis and in Fig. 16 to Octopus vulgaris; then, make two lateral incisions at the end point of the first incision, one towards the right and another towards the left, to expose the internal organs. If during this operation a long muscle that holds the mantle internally (it occurs in the octopuses) is found, it should be cut carefully and lengthwise, preventing damage of any internal organ. Exposure of the entire body cavity is required for assessment and allows access to organs for sampling. Once the internal organs are in sight, a preliminary and general inspection should be carried out. Notes on the general appearance of the cavity may include references to the extent of tissue growth or colour changes, swelling, ascites, adhesions, and absence of encysted parasites. As experience increases, all the procedures can be performed using scissors and scalpel.

The protocol that we recommend for the examination of the internal organs starts by carefully removal each one of them. After removal, each system should be placed in a Petri dish, which might be advisable to keep in a refrigerator $\left(4^{\circ} \mathrm{C}\right)$ for further examination. The most convenient order for the organs removal is as follows: $1^{\circ}$ ) the reproductive system (ovary, oviducts, and oviductal glands if there were, in the case of females; testicle, spermatophoric complex, and terminal organ (penis) in males); $2^{\circ}$ ) respiratory and main parts of the circulatory system (gills, branchial hearts, systemic heart, trying to conserve their connections through the associate blood vessels, as well as the most important vessels leaving the systemic heart, at least in part of their length). The excretory system is closely linked to these other two systems and is extracted together with them. Again, place these systems in a Petri dish and keep it in a refrigerator $\left(4^{\circ} \mathrm{C}\right)$ for further examination; $3^{\circ}$ ) the digestive system (oesophagus, posterior salivary glands, crop if present, stomach, caecum, digestive gland duct appendages, intestine and anus). If food remains are found in any part of the digestive system, it is convenient to remove them. The digestive gland and the ink sac are part of this system. As they break with relative ease, what we recommend to avoid its rupture is to keep them together with the other parts of the system, and, once in the Petri dish or in an appropriate tray, remove them carefully avoiding its rupture; $4^{\circ}$ ) the buccal mass (lips, two mandibles or beak, anterior salivary glands, buccal muscles, and radula) is relatively easy to extract using scissors and scalpel. Generally, when the buccal bulb is removed, fragments of the oesophagus remain. After these manipulations, the cuttlebone or the gladius can be removed.

Complete removal of the viscera is practical for easier assessment under a dissecting microscope, e.g. for parasitological analysis, however inappropriate, if aseptic microbiological samples are required. For tissue sampling and depending of necessities, whole organs may be fixed from small individuals (e.g. the entire gastrointestinal tract); conversely, from larger specimens portions of $\sim 1 \mathrm{~cm}^{3}$ of each organ should be removed and fixed. Bouin's fixative has been recommended for this tissue as gonads in an advanced stage of development can be hard to cut after routine formalin fixation. The digestive may vary in colour depending of the type of diet, as well as the health status of the specimen. A sample should be collected using a sharp scalpel rather than scissors. An examination of the gastrointestinal tract, caecum, and associated tissues can be carried out once relevant microbiological sampling has been performed.

Finally, the cranium needs to be opened in order to expose and examine the brain. One of the most appropriate ways to access the brain is: (1) fix the specimen on a dish, dorsal side up; 
(2) remove the skin of the head using a sharp scalpel; (3) remove the eyes, and the paired large optic lobes are located laterally and the white bodies over each optic lobe; (4) with a horizontal cut, remove the dorsal part of the cranium cartilage until the central part of the brain, a collection of very soft nerve tissue that actually surrounds the oesophagus, is visible. This mass corresponds to the supra and sub-oesophageal regions of the brain; (5) carefully remove the whole brain. The brain deterioration is rapid, and it is, therefore, important to fixing it. The two most common ways of fixing the brain are freezing and the use of fixative solutions. Each method has its advantages; (6) when all sub-oesophageal brain tissue is totally removed, the statocysts become visible. They are two cavities located at the posterior-ventral region of the cranium cartilage. Avoid damaging the thin cartilage between the brain and the statocyst cavities. When the anterior, lateral, and posterior outlines of the statocysts are visible, a block of cartilage containing the two statocysts can be cut out of the head. The statocysts can be also approaches from the ventral, which is the most appropriate way when operating with anesthetized animals. The tissue should fix for light microscopy or scanning electron microscopy. Statoliths are two white opaque structures located within the statocysts, which are using for ageing. It should be preserved dried or in ethanol $70 \%$.

Maintaining an organized and systematic approach to the necropsy is an important aspect of the procedure, and careful observations made during this examination will provide valuable information not only immediately, but consequently during the interpretation of the histological sections.

All tissues samples must be clearly identified with a reference code when sent for processing to ensure that there is no risk of incorrect reporting.

\subsection{Concluding Remarks}

As members of the phylum Mollusca, the cephalopods share certain basic features of their body organization. Despite their basic molluscan physiology and biochemical design, there are many characteristics in cephalopods that raise their lifestyle and performance to levels similar to those found in vertebrates. Cephalopods are active mobile predators, swimming by means of jet propulsion and fin undulations, or rapid scrambling by strong suckered arms. As in other molluscs, the central nervous system in arranges around the oesophagus. However, sense organs, particularly eyes and organs of balance (statocysts), are highly developed. Moreover, the brain does not just have centralization of the molluscan ganglia but also contains lobes with "higher-order" functions such as storage of learned information. Most of the cephalopods have a skin display system of unmatched complexity and excellence of camouflage, which is also used for communication with predators and conspecifics. In addition, the muscular systemic heart, the branchial hearts, and contractile blood vessels contributed to a strong blood circulation within a close circulatory system. The particularities set out here, which are not the only ones, require special knowledge of the morphology and gross anatomy of these organisms, when studies on their pathologies are focused. On the other hand, this type of knowledge is crucial when considering an adequate protocol for external and internal examination. Also its sacrifice, in the case that it would be necessary, must be considered attending to their particular characteristics.

Cephalopods also play an important role in the trophic web of marine ecosystems. The importance of cephalopods as hosts for parasites, which may travel up the food chain to top predators, such as marine mammals and man, has been emphasized elsewhere.

Finally, the growing importance of cephalopods in different research's fields, aquaculture, and human consumption requires a top priority and wider knowledge of their health. This knowledge includes detailed information about the cause, mechanisms of development (pathogenesis), morphological and anatomical alterations, and their clinical manifestations.

\section{References}

Andrews PLR, Darmaillacq A-N, Dennison N, Gleadall IG, Hawkins P, Messenger JB, Osorio D, Smith VJ, Smith JM (2013) The identification and management of pain, suffering and distress in cephalopods, including anaesthesia, analgesia and humane killing. J Exp Mar Biol Ecol 447:46-64. https://doi.org/10.1016/j.jembe. 2013.02.010

Arkhipkin AI, Rodhouse PGK, Pierce GJ et al (2015) World Squid Fisheries. Rev Fish Sci Aquac 23: 92-252. Taylor \& Francis Group, LLC, https://doi.org/10.1080/23308249.2015.1026226

Boyle PR, Rodhouse PGK (2005) Cephalopods. Ecology and Fisheries. Blackwell, London, p 452

Bruno DW, Noguera PA, Poppe TT (2013) A colour Atlas of salmonid diseases. Springer, Heidelberg

Darmaillacq A-S, Dickel L, Mater J (eds) (2014) Cephalopod cognition. Cambridge University Press, Cambridge, UK, p 247

Fiorito G, Affuso A, Basil J et al (2014) Cephalopods in neuroscience: regulations, research and the 3Rs. Invertebr Neurosci 14(1):13-36. https://doi.org/10.1007/s10158-013-0165-x

Guerra A (1992) Mollusca, Cephalopoda. In Ramos, MA et al (eds) Fauna Ibérica, vol. 1. Museo Nacional de Ciencias Naturales. CSIC, Madrid, p 318

Hanlon RT, Messenger JB (1996) Cephalopod behaviour. Cambridge University Press, Cambridge, U.K, p 232

Iglesias J, Fuentes L, Villanueva R (eds) (2014) Cephalopod culture. Springer, Heidelberg, p 494

Jereb P, Roper CFE (eds) (2005) Cephalopods of the world. An annotated and illustrated catalogue of cephalopods species known to date. Chambered nautiluses and sepioids. FAO Species Catalogue for Fisheries Purposes, No 4, vol. 1. Rome, p 262 
Jereb P, Roper CFE (eds) (2010) Cephalopods of the world. An annotated and illustrated catalogue of cephalopods species known to date. Myopsid and Oegopsid squids. FAO Species Catalogue for Fisheries Purposes, No 4, vol. 2. Rome, p 605

Jereb P, Roper CFE, Norman MD, Finn JK (eds) (2016) Cephalopods of the world. An annotated and illustrated catalogue of cephalopods species known to date. Octopods and Vampire squids by. FAO Species Catalogue for Fisheries Purposes, No 4, vol. 3. Rome, p 352

Mangold K (1989) Céphalopodes. In: Grassé PP (ed) Traité de Zoologie, vol 4. Masson, Paris, p 804
Nixon M, Young JZ (2003) The brains and lives of Cephalopods. Oxford University Press, Oxford, UK, p 392

Pörtner HO, O'Dor RK, Macmillan DL (1994) Physiology of Cephalopod Molluscs: lifestyle and performance adaptations. Gordon and Breach Publishers, Basel, Switzerland, p 214

Young JZ (1971) The anatomy of the nervous system of octopus vulgaris. Clarendon Press, Oxford, p 690

Young RE, Vecchione M, Mangold KM (2018) Cephalopoda Cuvier 1797. Octopods, squids, nautiluses, etc. Version 20 (under construction). http://tolweb.org/Cephalopoda/19386/2018.02.20 in The Tree of Life Web Project, http://tolweb.org/ Accessed Sept 8 2018
Open Access This chapter is licensed under the terms of the Creative Commons Attribution 4.0 International License (http://creative commons.org/licenses/by/4.0/), which permits use, sharing, adaptation, distribution and reproduction in any medium or format, as long as you give appropriate credit to the original author(s) and the source, provide a link to the Creative Commons licence and indicate if changes were made.
The images or other third party material in this chapter are included in the chapter's Creative Commons licence, unless indicated otherwise in a credit line to the material. If material is not included in the chapter's Creative Commons licence and your intended use is not permitted by statutory regulation or exceeds the permitted use, you will need to obtain permission directly from the copyright holder. 